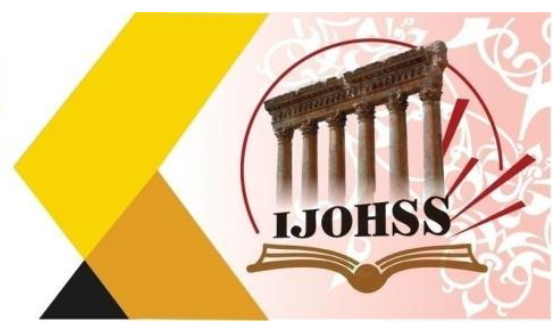

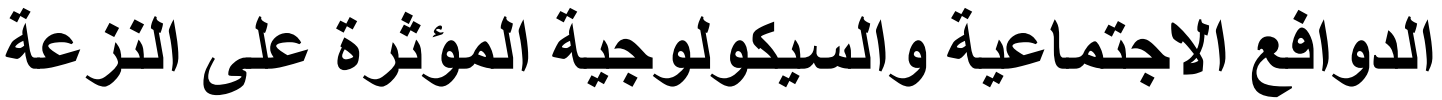

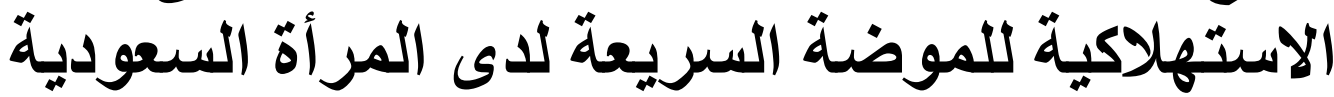

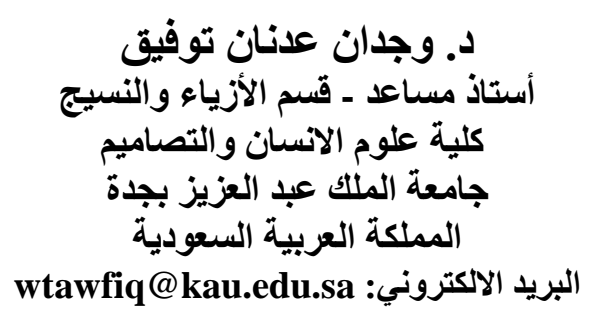

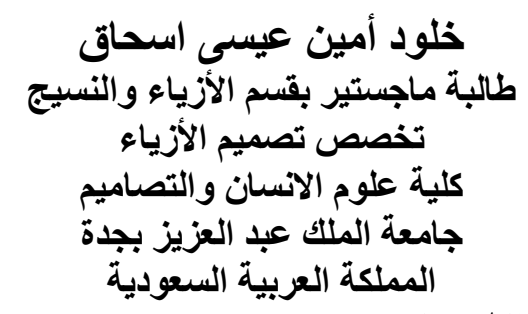

البريد الاكتروني: keishaque@stu.kau.edu.sa

الملخص

يتجه العالم اليوم نحو تحقيق الاستدامة في جميع المجالات، بما في ذللك مجال الموضة والأزياء. ولأن الموضة السريعة تعتبر من أهم الأسباب التي تعوق استدامة مجال صناعة الأزياء، ولأن المستهلك هو القوى التي تحرك جميع الصناعات، فإن معرفة أسباب تفتي النزعة الاستهلاكية للموضة السريعة سيساهم في زيادة الوعي عن الون الاستهلاك الأخلافي ويعزز أهداف التنمية المستدامة. لذا يهدف هذا البحث إلى معرفة أثر كلاً من الدوافع السيكولوجية والاجتماعية على النزعة الاستهلاكية للموضة السريعة لدى المرأة السعودية. اتبع البحث المنهج الوصفي التحليلي وطورت الباحثة نموذج لقياس فرضيات البحث. بلغ حجم العينة 600 امر أة سعودية من خلفيات اجتماعية وثقافية مختلفة. أجرت الباحثة التحليل العاملي التوكيدي واختبار معادلة النمذجة البنائية باستخدام برنامج التحليل الاحصائي Spss و Amos للتوصل الى النتائج، و التي كان من أهمها: وجود اختلافات في درجة

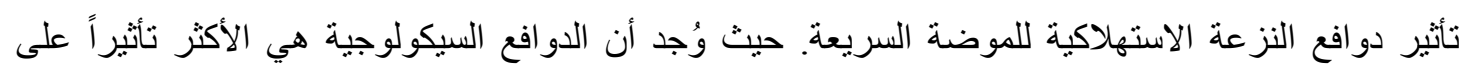

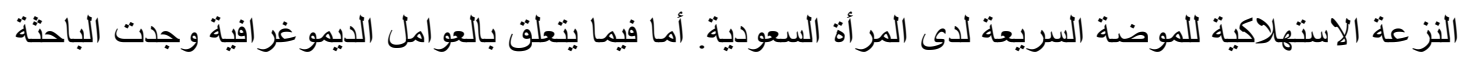

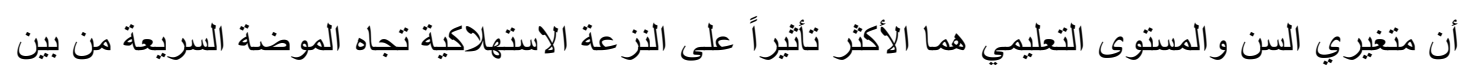

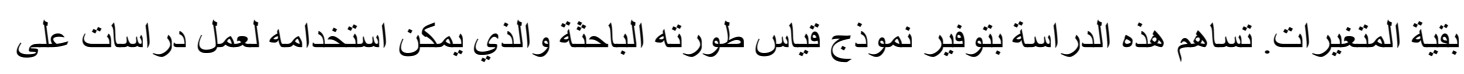

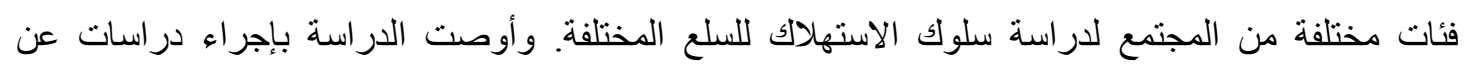
الاستهلاك الاخلاقي و الموضة المُستدامة في المجتمع السعودي.

الكلمات المفتاحية: النزعة الاستهلاكية، الموضة السريعة، المستهلك السعودي، الدوافع السيكولوجية، الدوافع

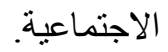




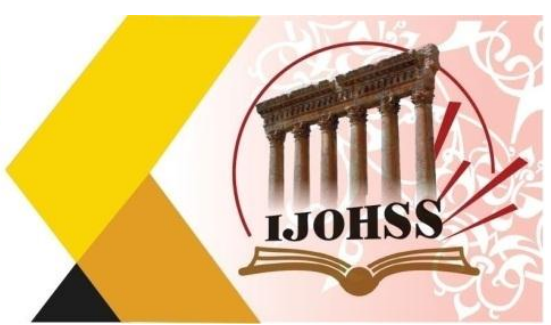

\title{
Social and Psychological Motives
} Affecting The Consumerism of Fast Fashion among Saudi Women

\author{
Khulood Ameen E Ishaque \\ Master's student in the Department of \\ Fashion Design, Faculty of Human \\ Sciences and Design, King Abdul-Aziz \\ University, Jeddah, Saudi Arabia \\ Email: keishaque@stu.kau.edu.sa
}

\author{
Wijdan Adnan Tawfiq \\ Assistant Professor in the Department of \\ Fashion Design, Faculty of Human \\ Sciences and Design, King Abdul-Aziz \\ University, Jeddah, Saudi Arabia \\ Email: wtawfiq@kau.edu.sa
}

\begin{abstract}
Over the last decade, the international recognition of sustainability has been growing in many disciplines, including fashion and textiles discipline. The fast fashion industry is one of the most unsustainable and polluting industry that impede the sustainability in the industry. Since the consumer is the center of this fashion industry, it is important to understand how fast fashion affects consumers around the world, which in turn will contribute to raising the awareness about ethical consumption and promoting sustainable fashion. Thus, the purpose of this research was to identify the psychological and the social motives that affects fast fashion consumerism among Saudi females' consumers. A quantitative descriptive method approach was applied to collect the data via web-based survey from 600 Saudi females from various social and cultural backgrounds. To measure the research hypotheses, a measurement model was developed by conducting the confirmatory factor analysis (CFA) and the structural equation modeling (SEM) using SPSS \& Amos software. Finding reveled significant differences between the psychological and the social motives that affects fast fashion consumerism among Saudi females' consumers. It was found that the psychological motives have the strongest influence on the consumerism of fast fashion among Saudi females. As for the demographic factors, the researcher found that the age and educational level are the most influential variables on consumerism of fast fashion. The main contribution of this study is developing a measurement model which can be used to conduct more studies about consumerism on different groups of consumers. Future work should be exploring ethical consummation and sustainable fashion among Saudi consumers.
\end{abstract}

Keywords: Consumerism, fast fashion, Saudi consumers, psychological motives, social motives. 
العدد (30) فبراير 2022

Volume (30) February 2022

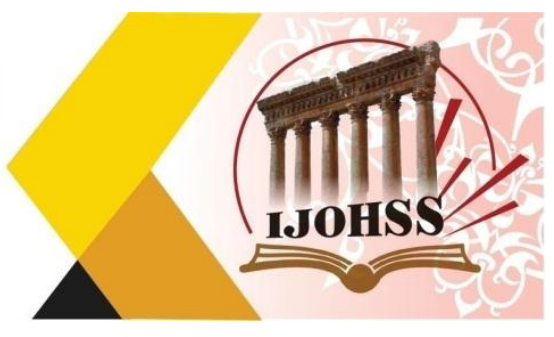

ISSN: $2415-4822$

المقدمـة

يعد موضوع الاستهلاك من المواضيع التي حظيت باهنمام كبير من قبل الباحثين في مجال العلوم الاقتصادية،

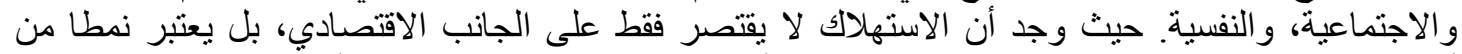

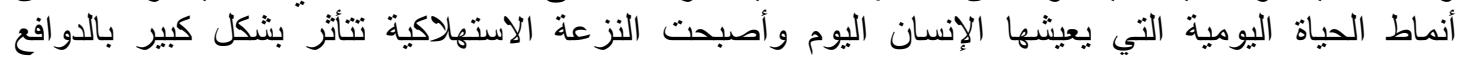

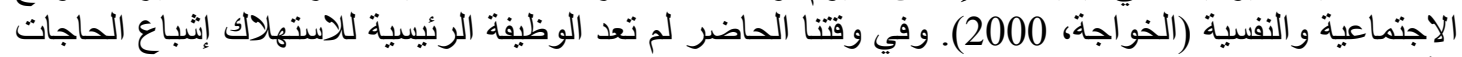

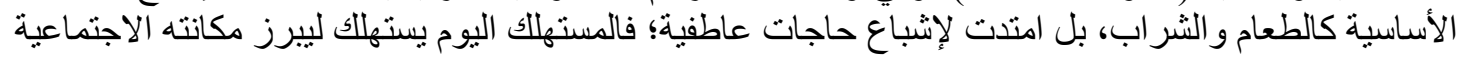

وييني هوينه (Douglas \& Isherwood, 1978 ; Pronay \& Hetesi, 2016)

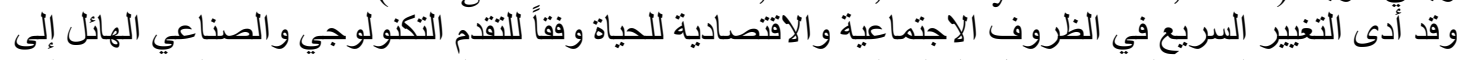

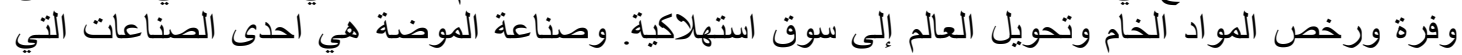

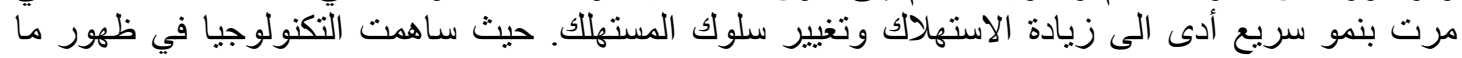

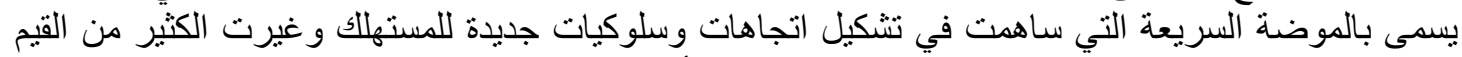

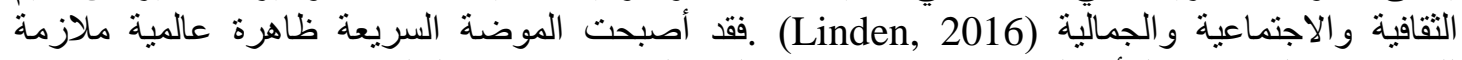

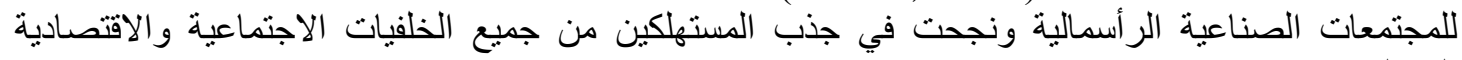

المختلفة (Barnes \& Lea-Greenwood, 2006 (Binden, 2016).

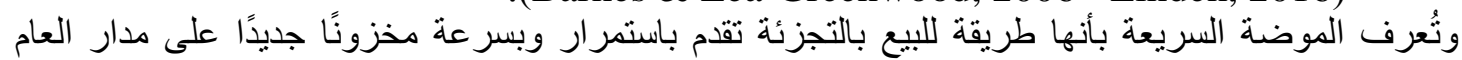

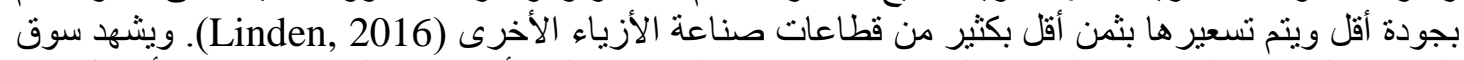

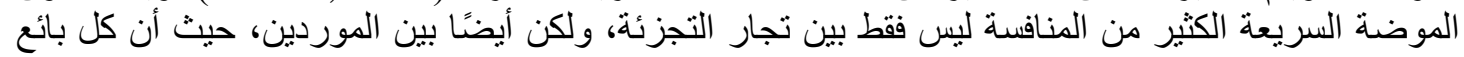

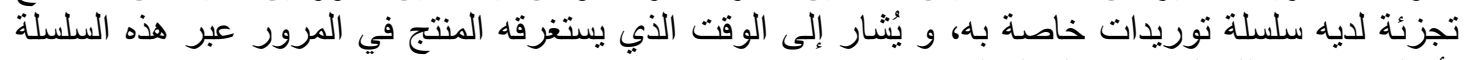

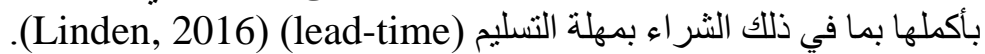

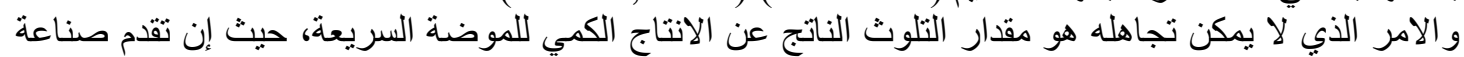

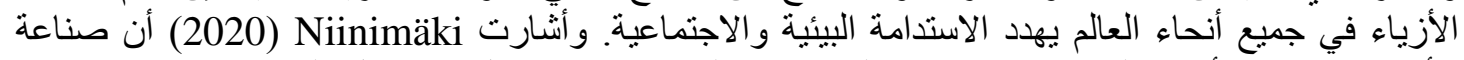

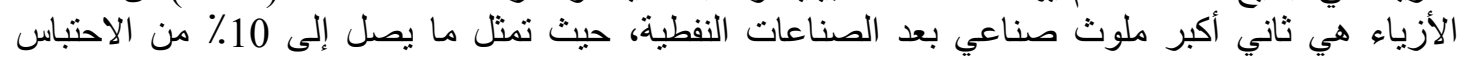

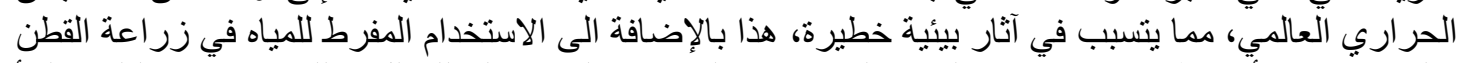

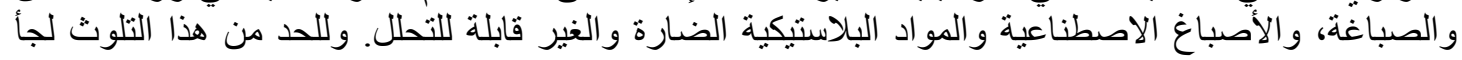

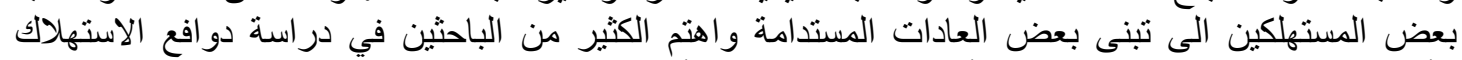

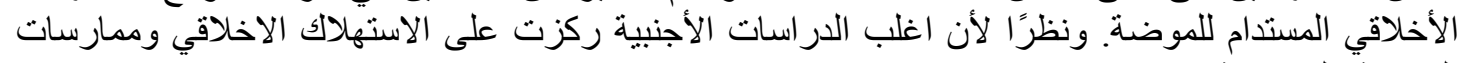

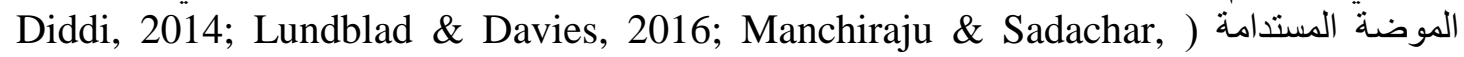
المعاد 2018 (2014; Razzaq, el. السعودي لان فهم دوافع السلوك الاستهلاكي سيساهم في تحويل هذا السلوك الاستهلاكي الى سلؤك اخلافي الحئي

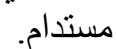
وركزت الدر اسات التي اهتمت باستهلاك الازياء المستدام على استكثاف ما إذا كانت القيم الثخصية تؤثر في

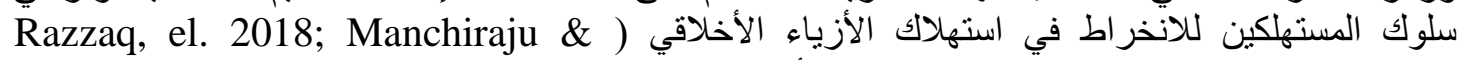

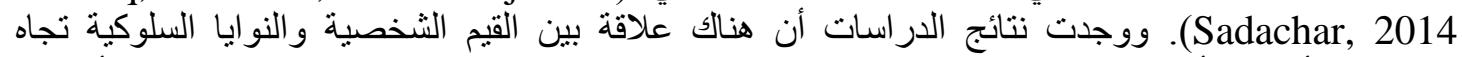

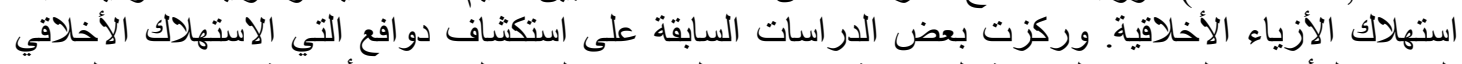

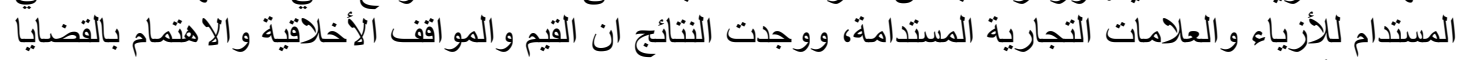

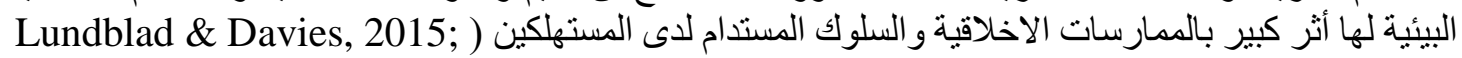

.(Diddi, 2014

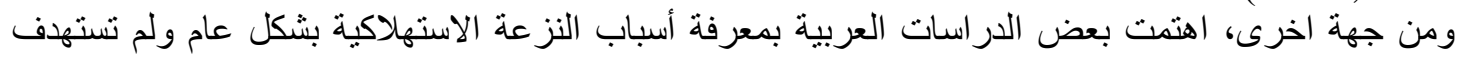

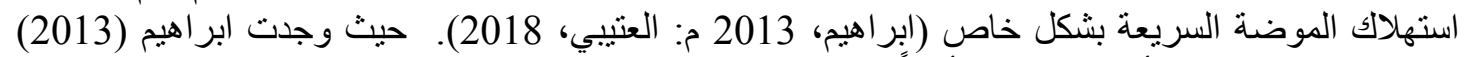

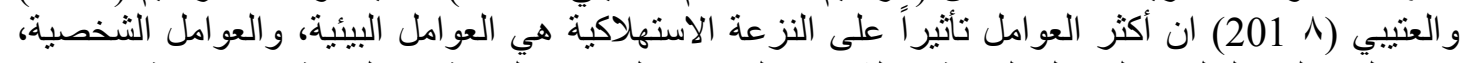

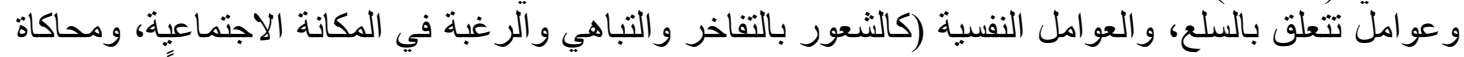

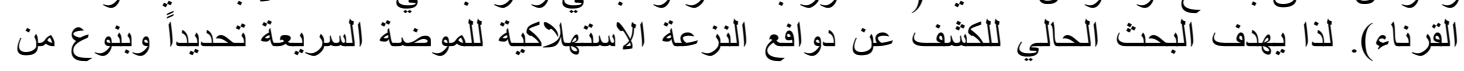




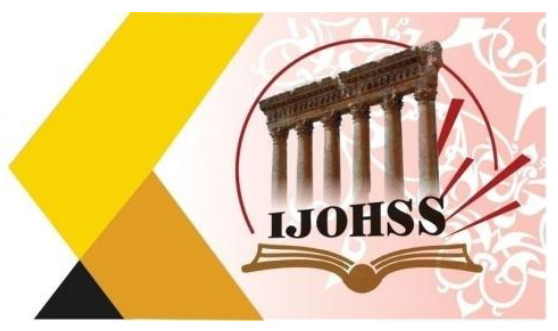

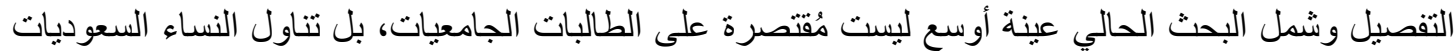

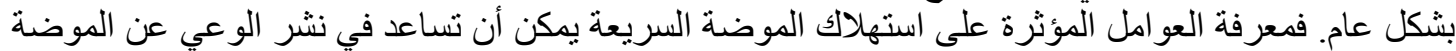
البطيئة المستدامة وتغير نمط السلوك الاستهلاكي لدي المر آة السعودية.

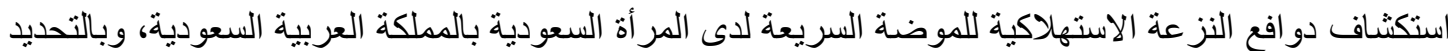

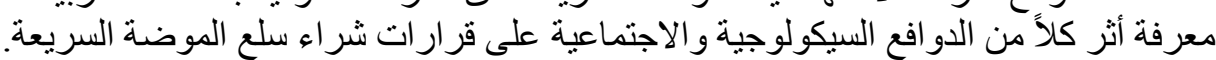

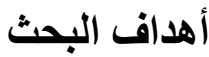

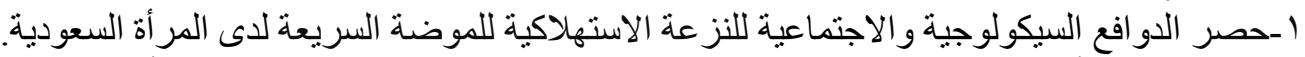

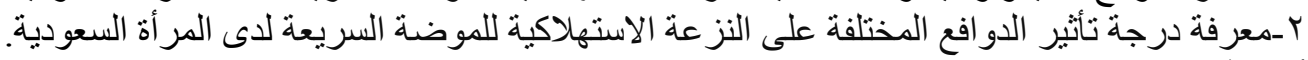

أهمية البحث دئن

1-إثر اء المحتوى العلمي فيما يتعلق بالموضة السريعة و الدو افع المساهمة في تشكيل النزعة الاستهلاكية.

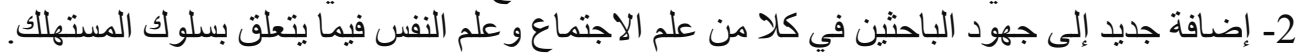

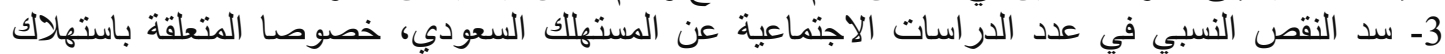
الموضة السريعة.

4- مساعدة مسوقي الموضة البطيئة وصناع القرار في مجال الموضة البطيئة و المستدامة.

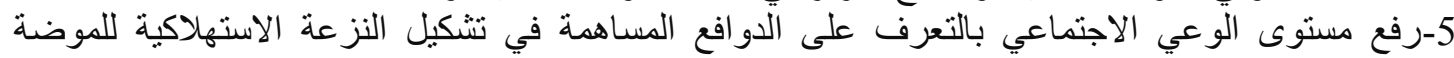

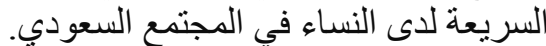

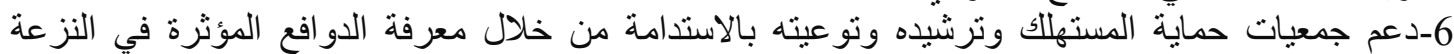
السلوكية للموضة السريعة. م ف فرض نوجد علاقة ذات دلالة إحصائية بين الدوافع السيكولوجية والنزعة الاستهلاكية (قرار الثراء) للموضة السريعة لدى المر أة السعودية. O

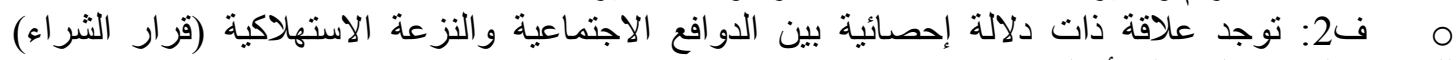
للموضة السريعة لدى المر أة السعودية.

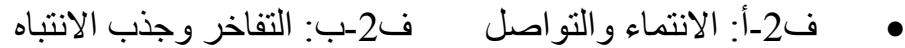

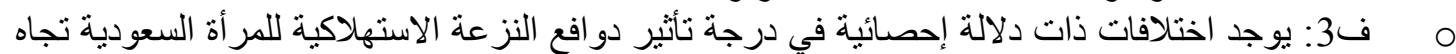
الموضة السريعة. م ف4: تؤثر العوامل الديموغرافية (الدخل ـالسن ـالتعليم- مكان الاقامة) على النزعة الاستهلاكية (قرار الثراء) للموضة السريعة لاى المر أة السعودية.

\section{الإطار النظري نظريات البحث}

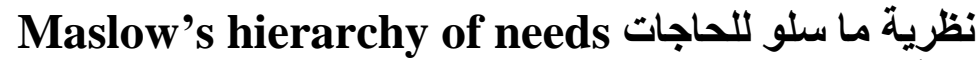

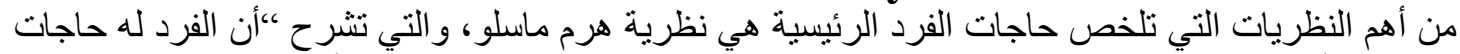

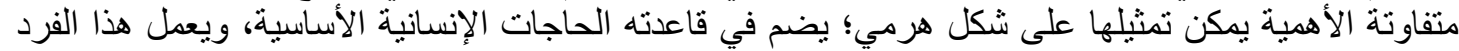

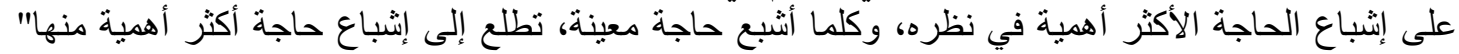

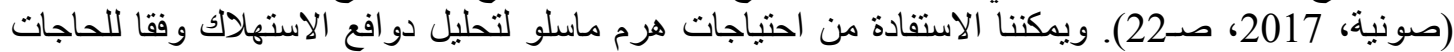

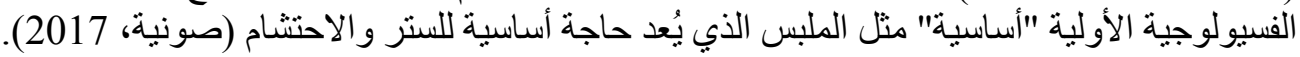




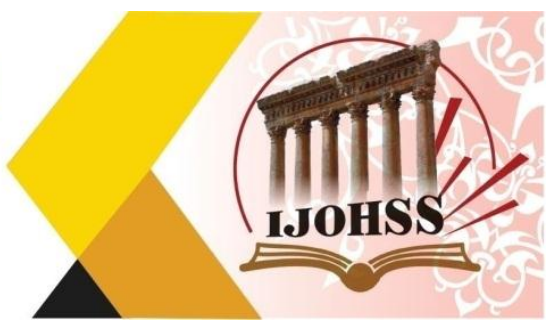

ويمكن أن نربط الحاجات الاولية بهرم ماسلو بالسلع النفعية الوظيفية (Utilitarian goods) وتعرف بالسلع (S) ونها التي يكون استهلاكها بهدف انجاز مهمة وظيفية أو عملية (Strahilevitz \& Myers, 1998). وتضم هذية النهات

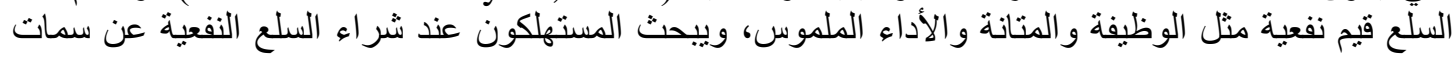

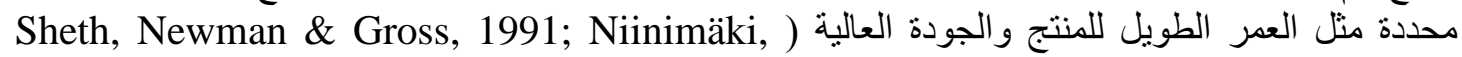

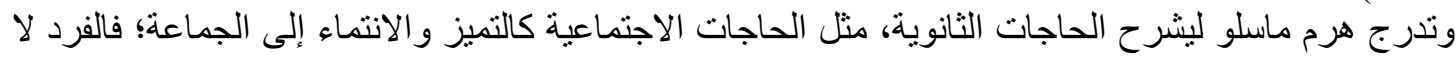

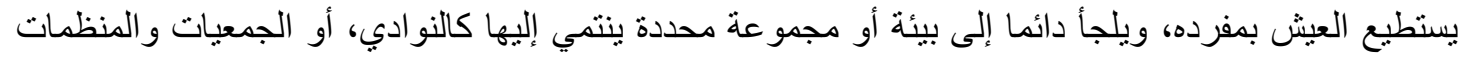

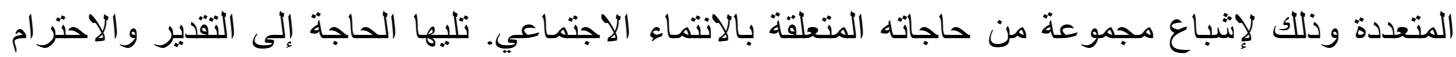

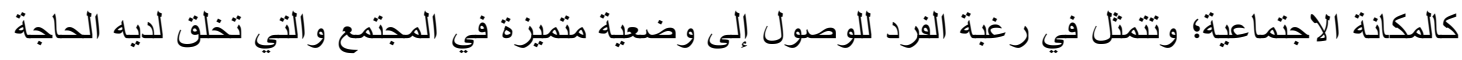

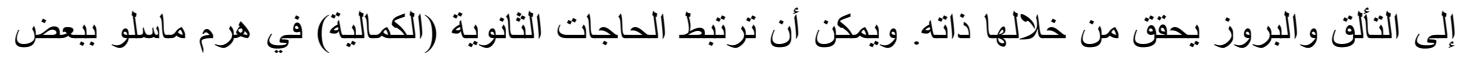

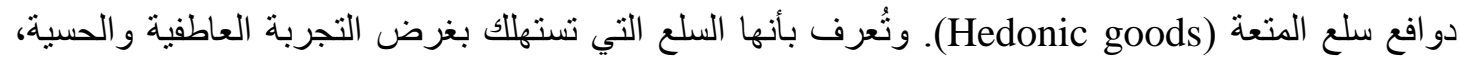

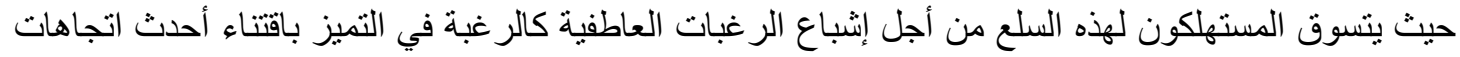

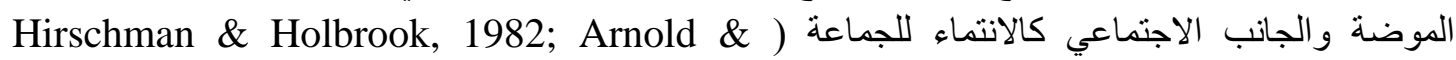

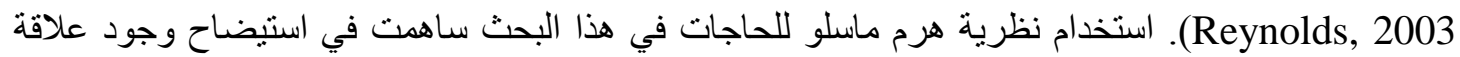

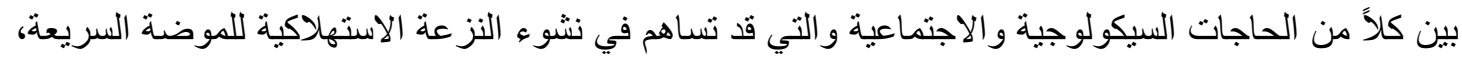

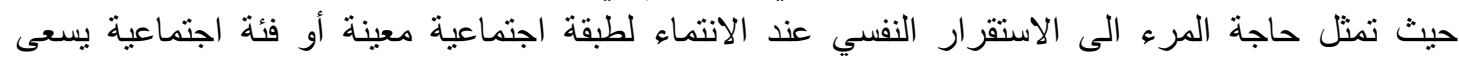

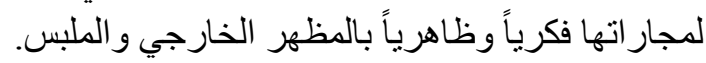

\section{نظرية الاستهلاك الرمزي Symbolic Consumption by Levy}

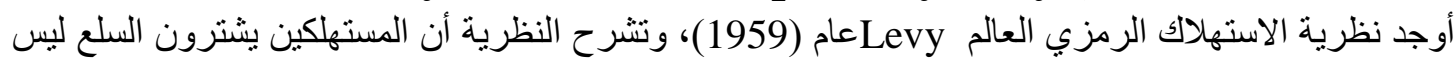

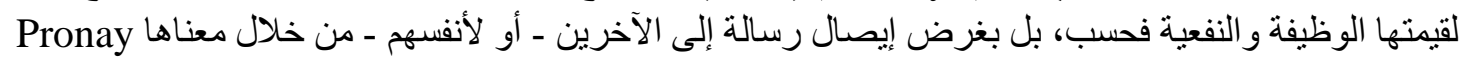

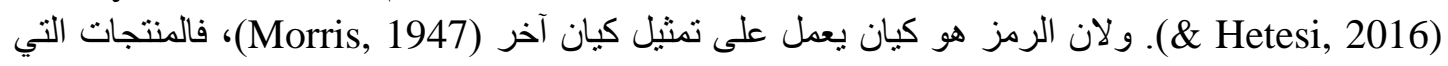

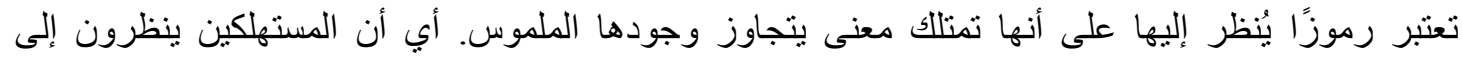

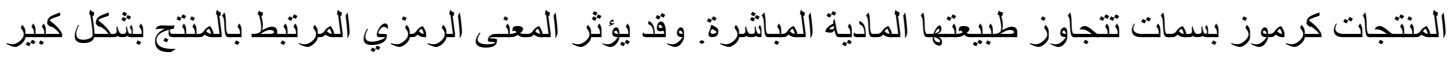

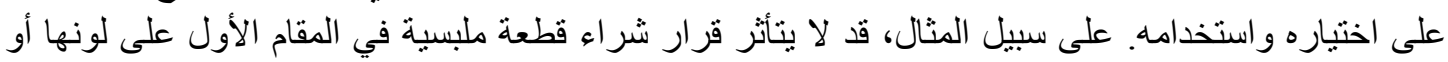

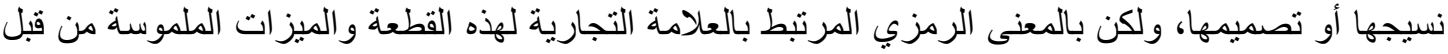

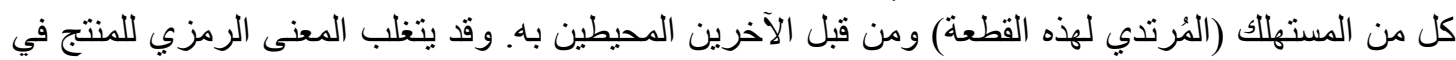

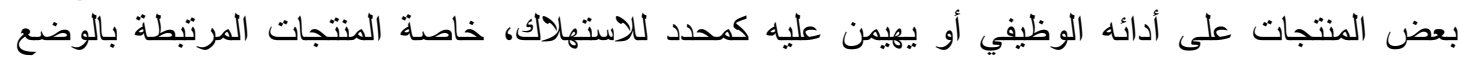
الاجتماعي أو الهوية الذاتية منل السيارات، و الأزياء، و المكملات (Hirschman,1918).

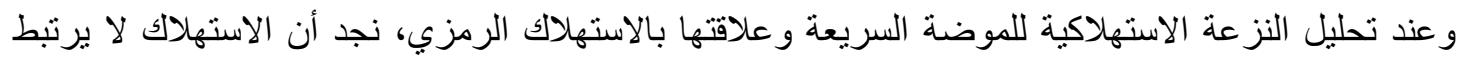

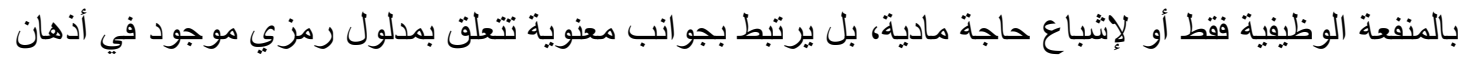

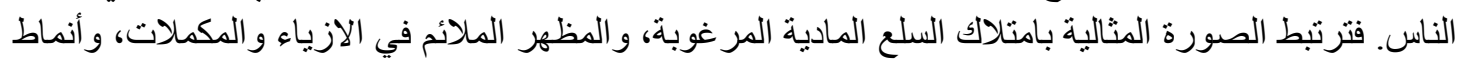

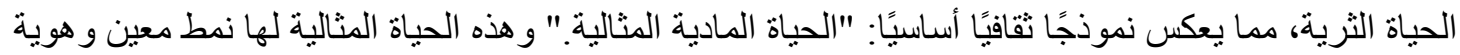

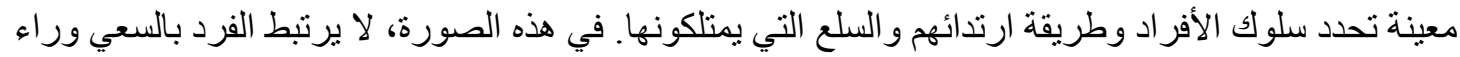

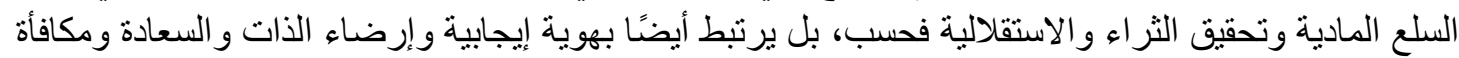

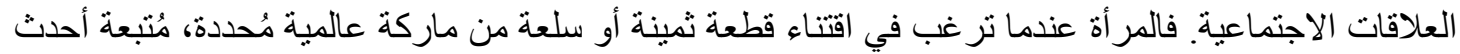

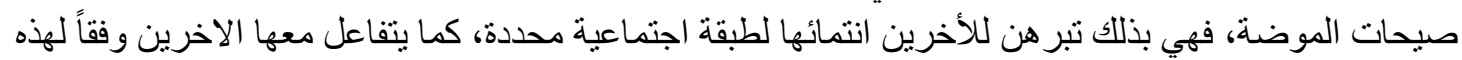

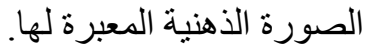


العدد (30)

Volume (30) February 2022

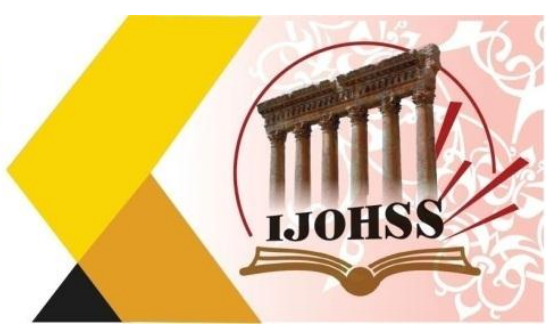

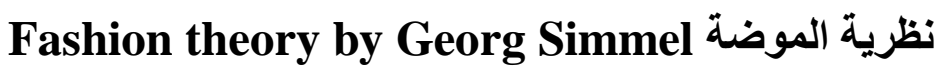

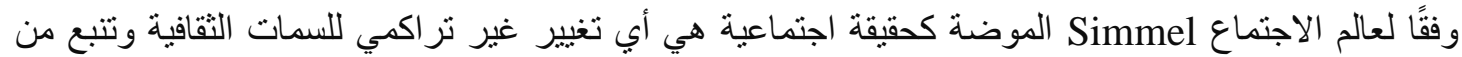

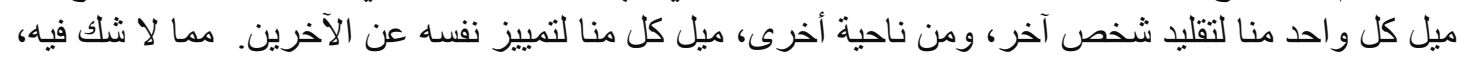

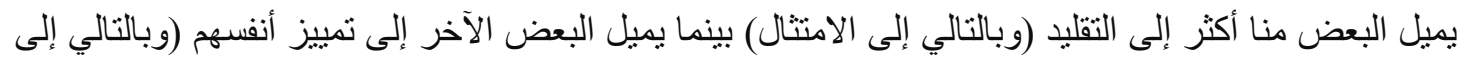

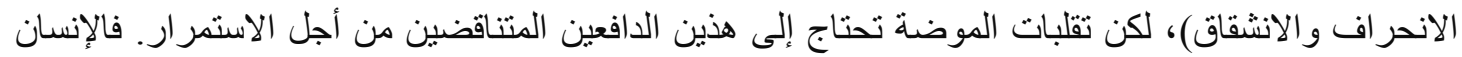

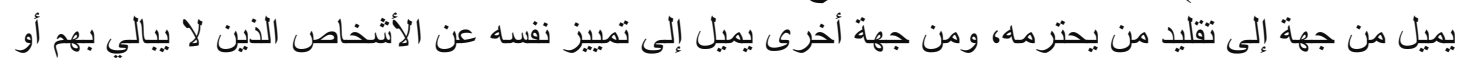

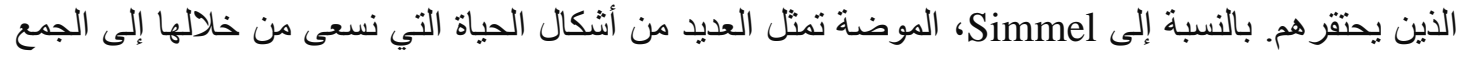

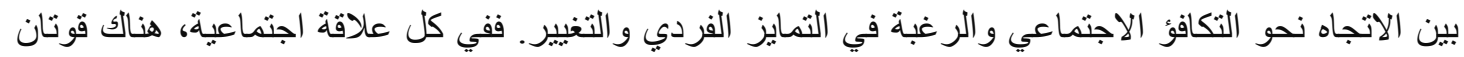

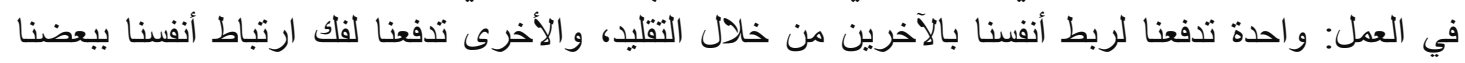
البعض، لفاك الثبكة الاجتماعية، من خلال تمييز أنفسنا عن الآخرين (Benvenuto, 2000).

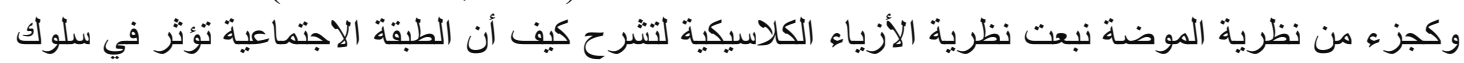

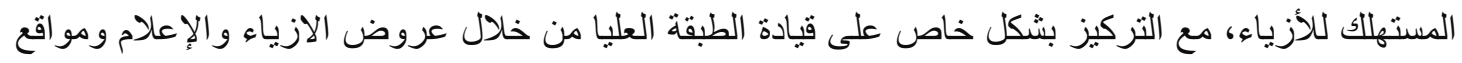

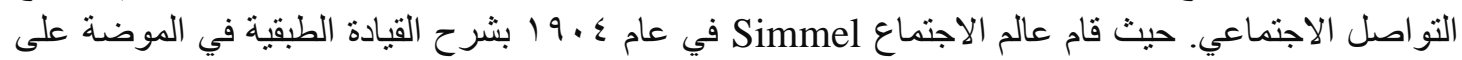

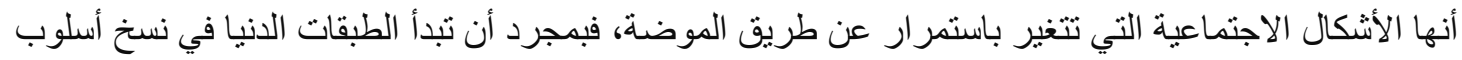

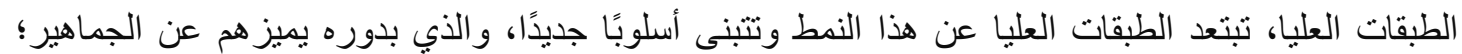

و وهكا تستمر اللعبة (Sproles, 1974).

وبناء على نظرية الموضة ونظرية الاستهلاك الرمزية فإن الحية الحاجة إلى التميز والتفرد من خلال المظهر

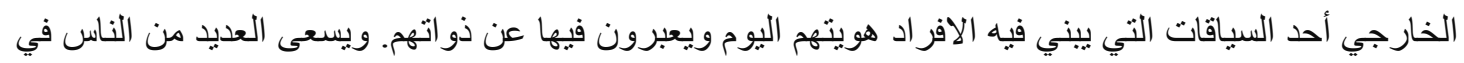

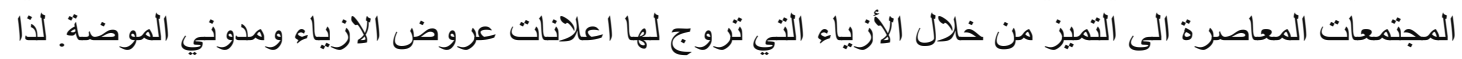

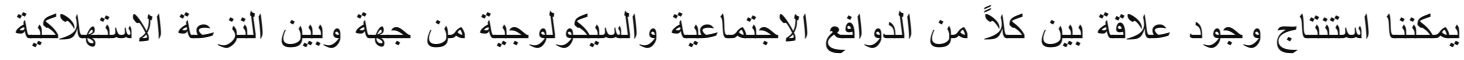

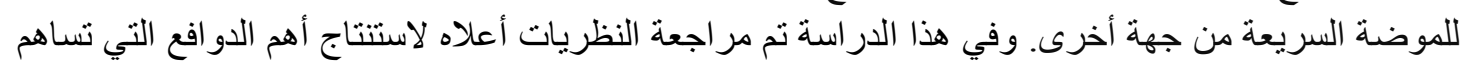

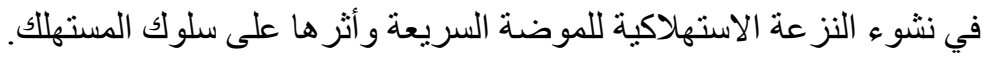

قامت الباحثة برسم هيكلة للنظريات المستخدمة في هذا البحث (شكل رقم 1)، لشرح كيفية ارتباط دو افع النزعة

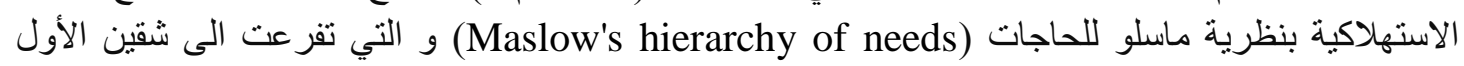

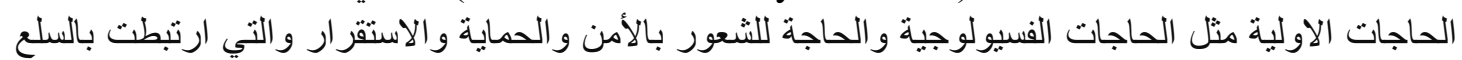

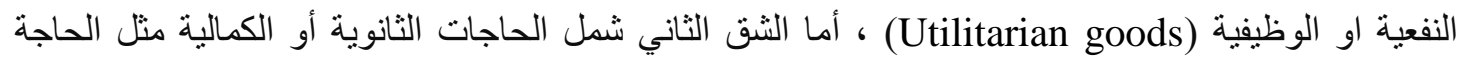

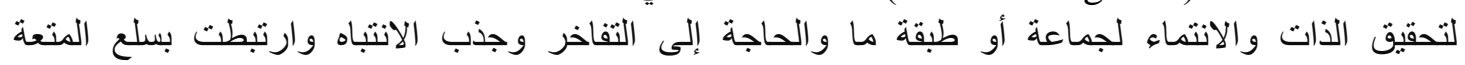
Symbolic (Hedonic goods) Consumption By Levy

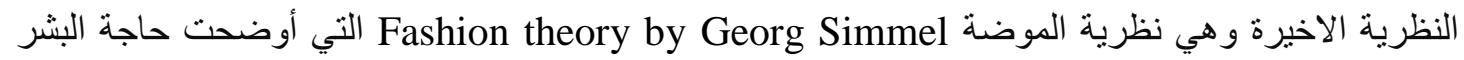

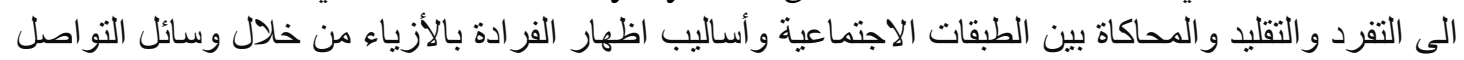

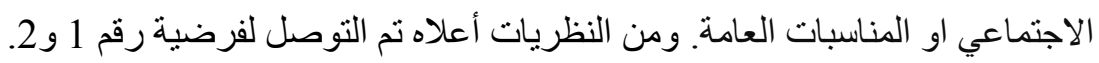



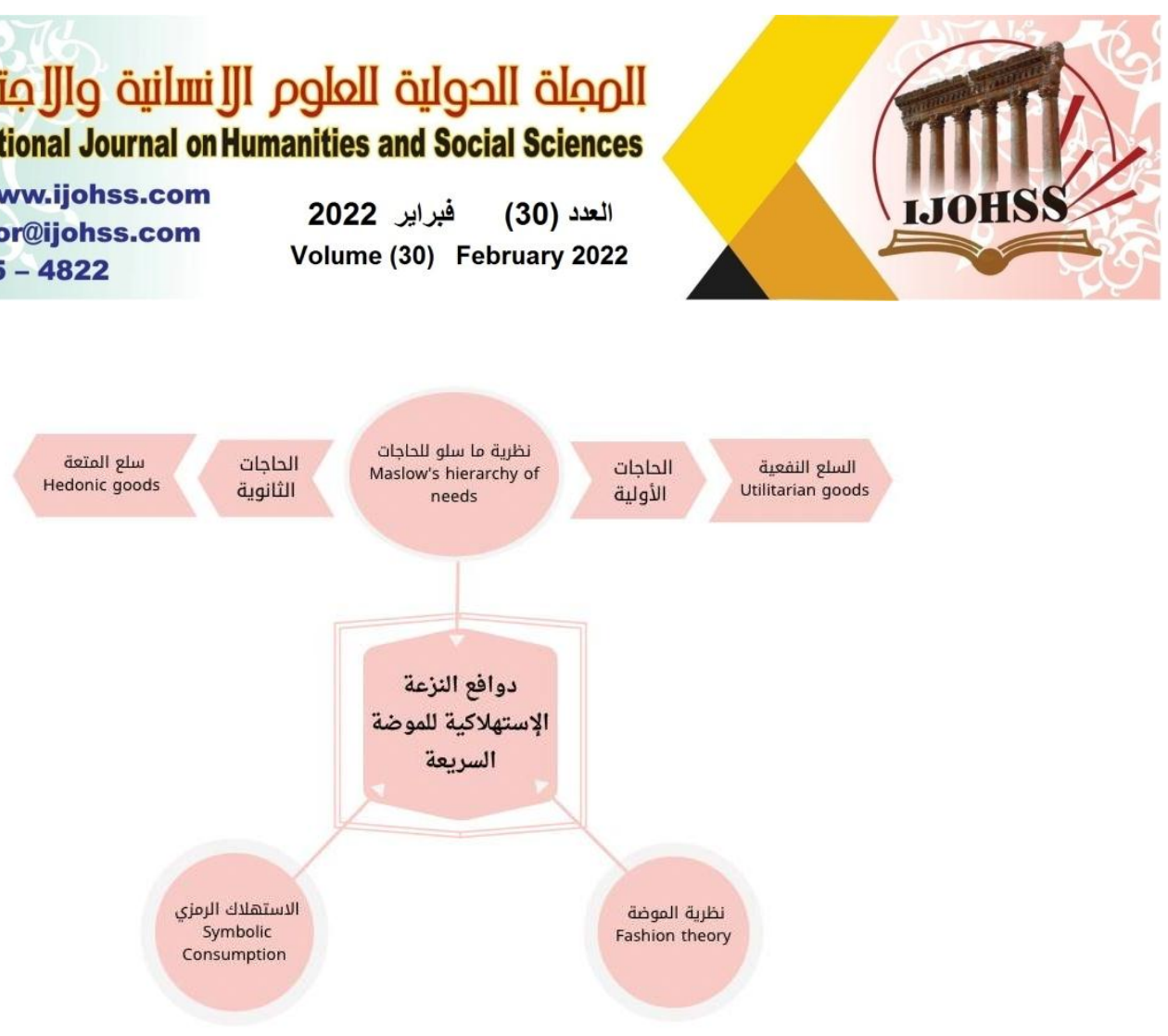

شكل (1) هيكلة نظريات البحث

دوافع النزعة الاستهلاكية

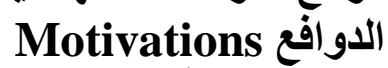

يعرف الدافع "أنه قوة وشعور داخلي يحرك وينشط سلوك الفرد لإثباع حاجات ورغبات الإنبات معينة من أجل تخفيف

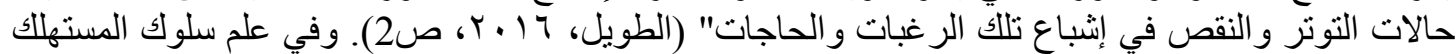

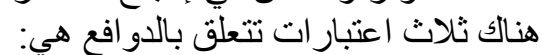

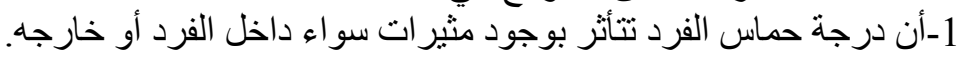

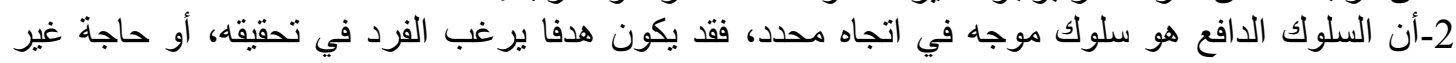
مشبعة يريد إثباعها. بَ-إن درجة إثباع هذه الحاجات قد نؤدي إلى تكرار السلوك، أو تغييره، أو تثبيته، أو تحويله إلى سلوك هادف

$$
\begin{aligned}
& \text { كما قسم الباحث (Mc. Guire) الدو افع إلى نو عين: } \\
& \text { أـ الدو افع الداخلية غير الاجتماعية الإناعية } \\
& \text { بـ الدو افع الخارجية الاجنماعية (المجني و عمار، 2020). }
\end{aligned}
$$

Consumerism النزعة الاستهلاكية الإيزة

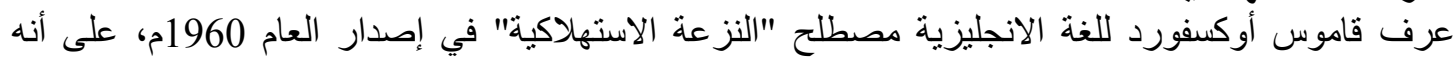

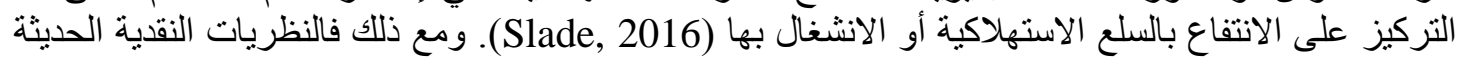

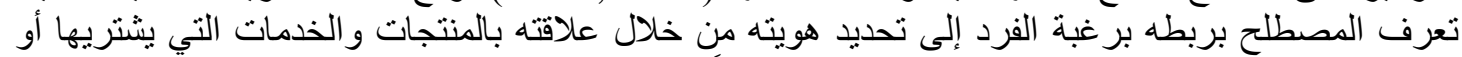

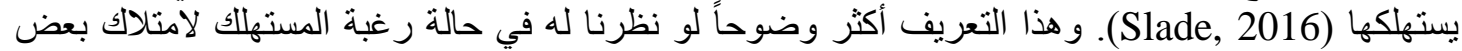

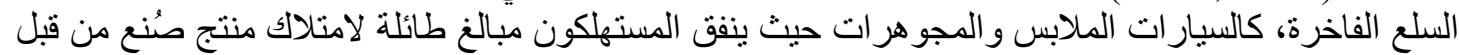
علامة تجارية معينة (Slade, 2016). 
العدد (30) فبراير 2022

Volume (30) February 2022

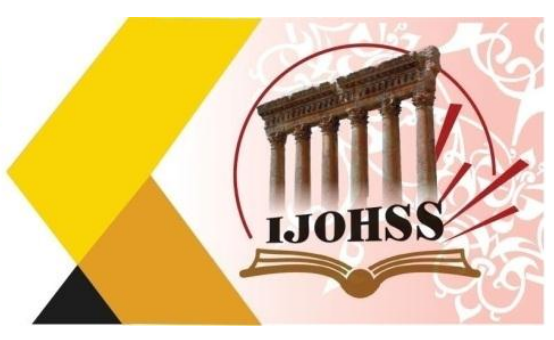

دوافع الاستهلاك السيكولوجية

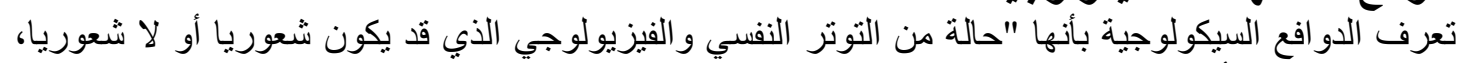

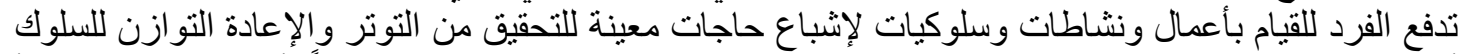

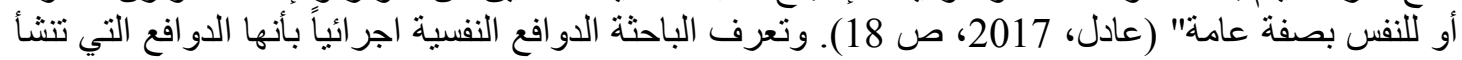

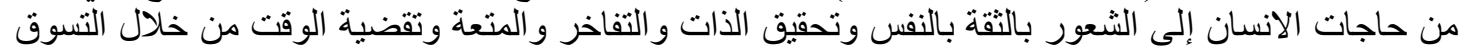

و الاستهلاك المفرط للموضة الأنسان السريعة.

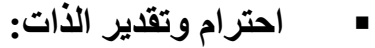

مفهوم تقدير الذات يثير إلى إدراك الكرد الفرد أو التقيبم الذاتي لقيمته الذاتية، ومشاعره باحتر ام الذات و الثقة بالنفس

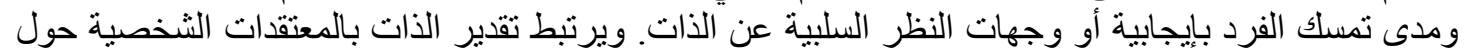

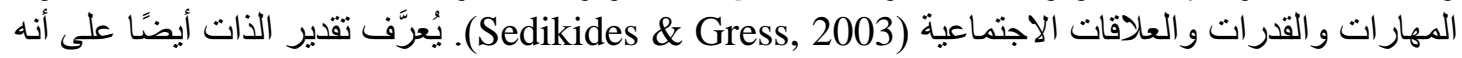

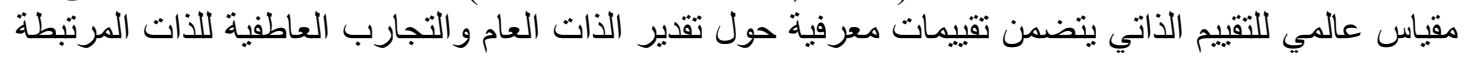

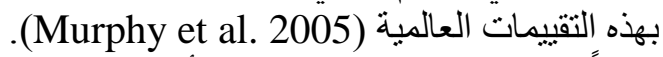

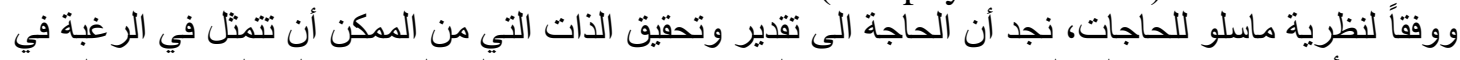

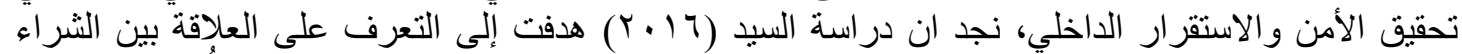

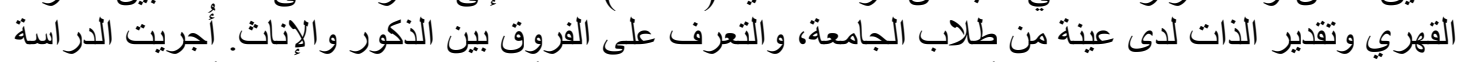

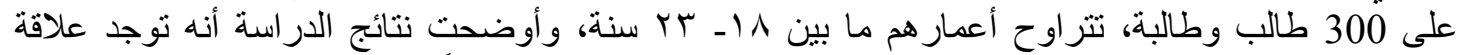

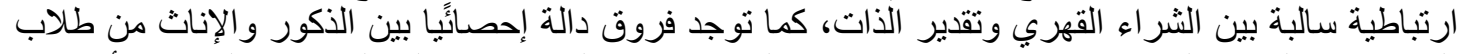

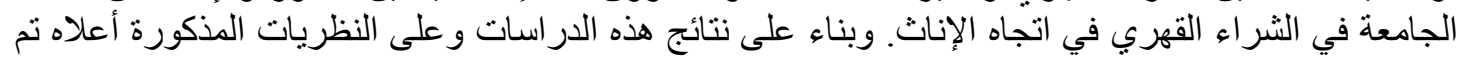

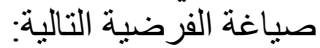

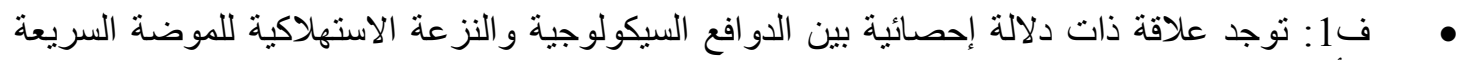

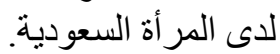

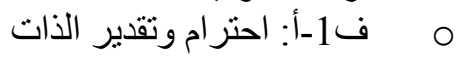

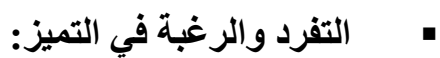

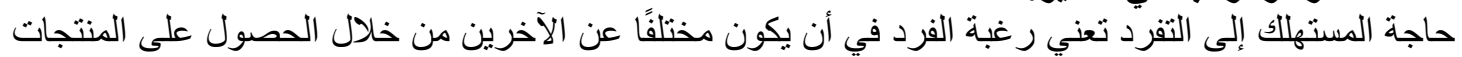
و العلامات التجارية التي تعزز الصورة الشخصية والاجتية التماعية للفرد (Tian, Bearden \& Hunter, 2001).

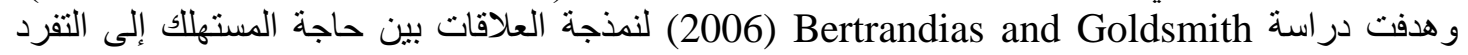
والاهتمام بمعلومات المقارنة الاجتماعية من خلال الاشخاص الذين يقودون الموضة ( Fashion Opinion

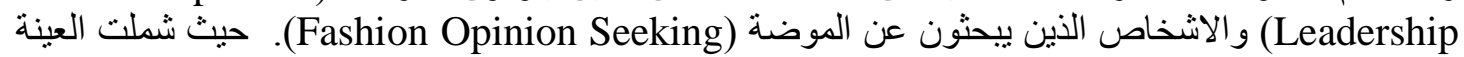

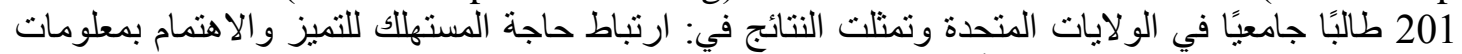

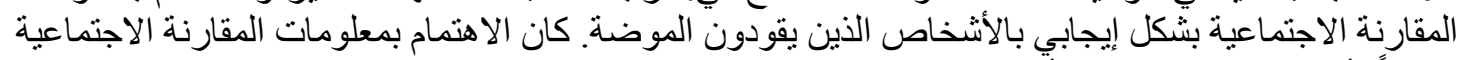

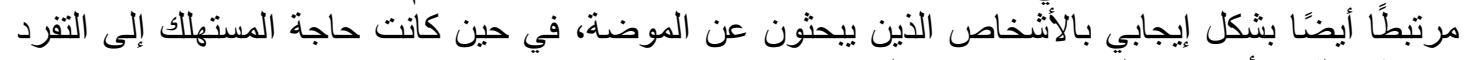

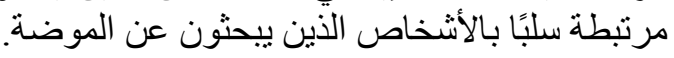

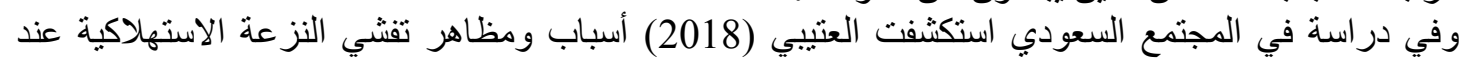

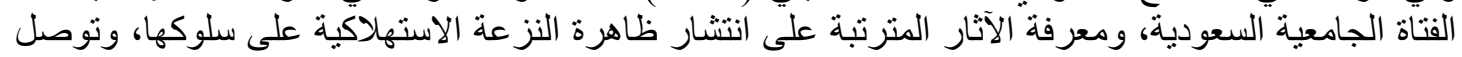

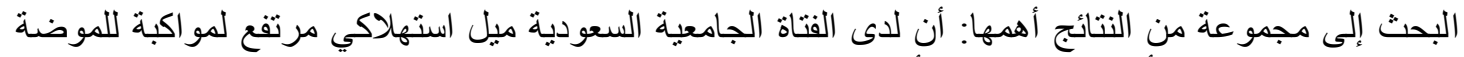

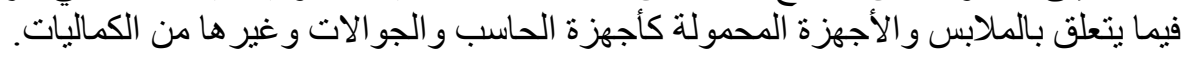

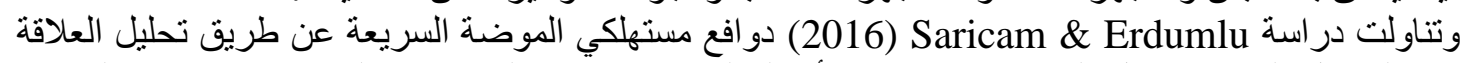

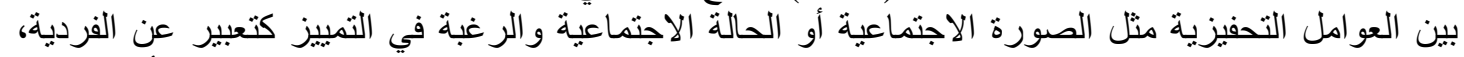

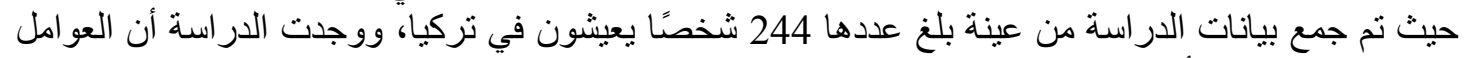

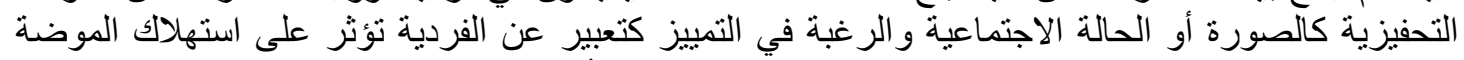

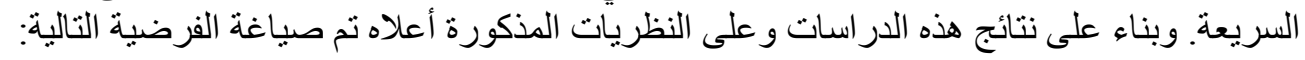


• 1: نوجد علاقة ذات دلالة إحصائية بين الدوافع السيكولوجية والنزعة الاستهلاكية للموضة السريعة

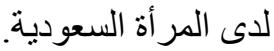

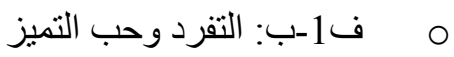

دوافع الاستهلاك الاجتماعية

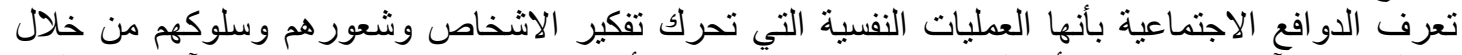

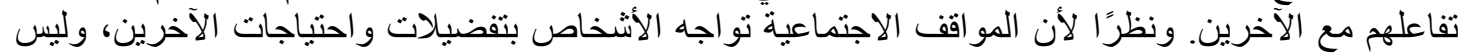

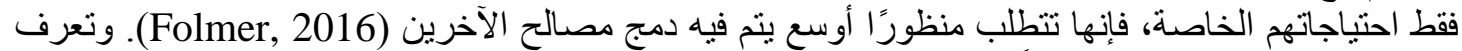

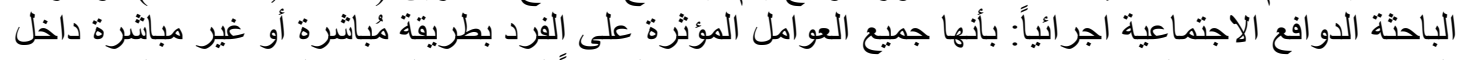

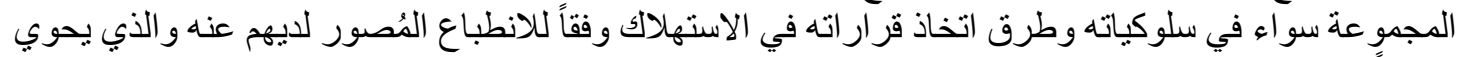

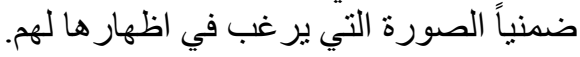

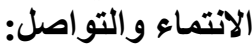

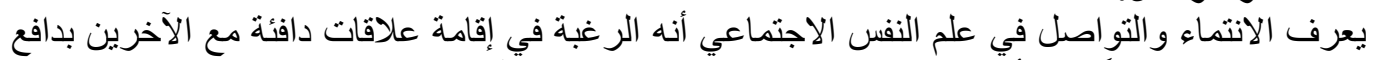

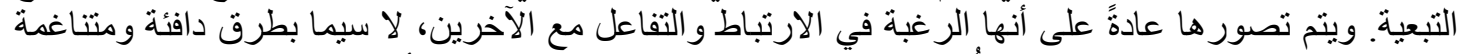

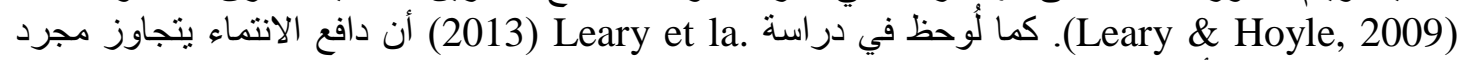

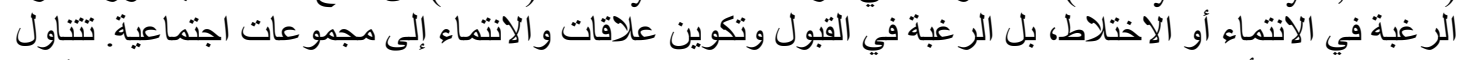

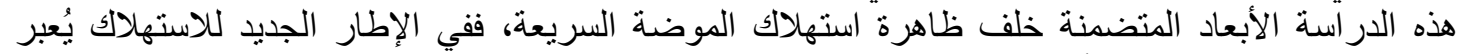

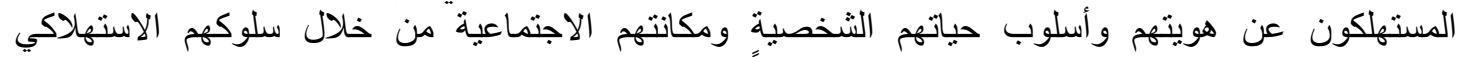

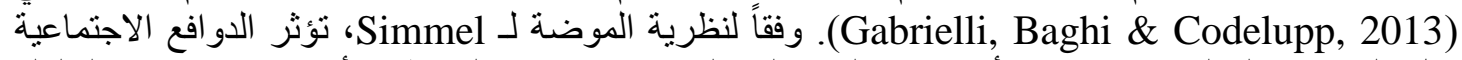

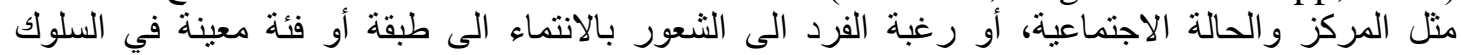

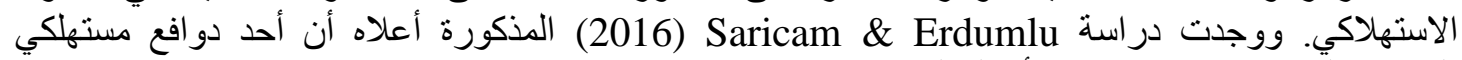

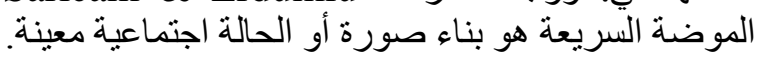

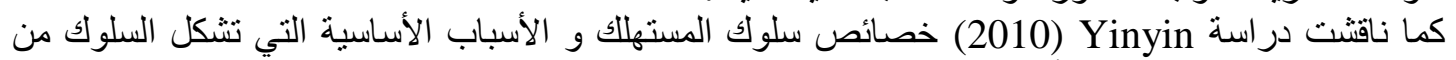

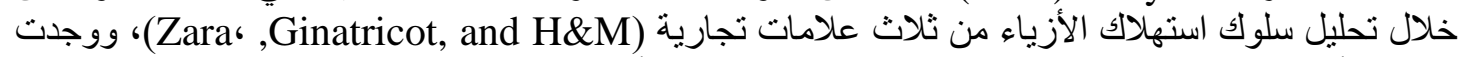

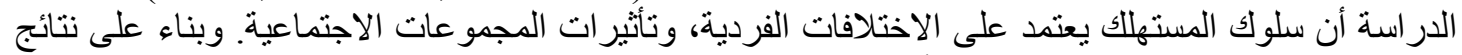

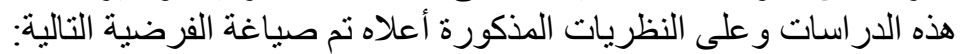

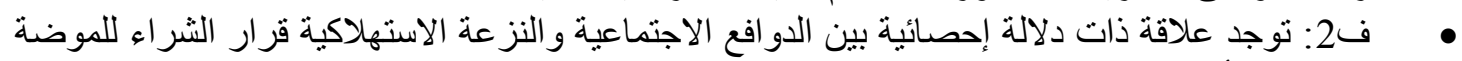
السريعة لاى المر أة السعودية.

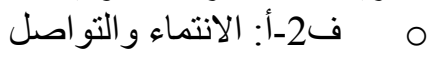

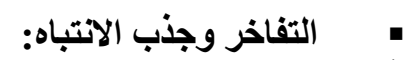
عُرف التفاخر ومحأولة جذب الأب الانتباه بأنه نوع من القلق، وقسّم التفاخر إلى أربعة أقسام: الاهتمام المادي،

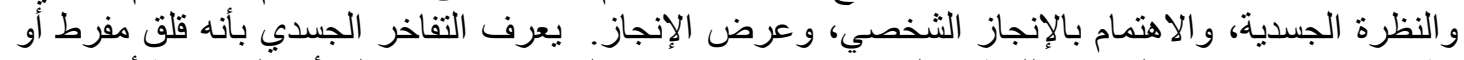

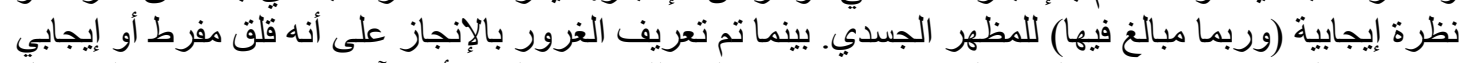

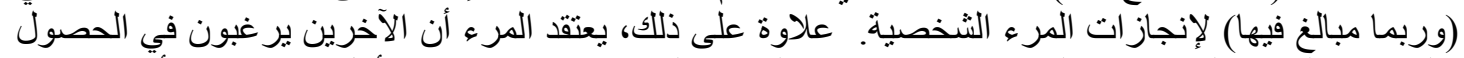

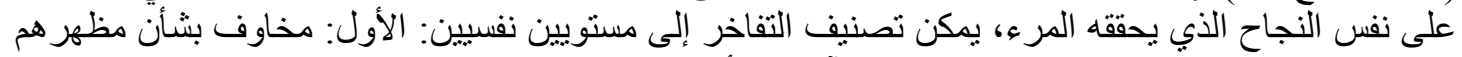

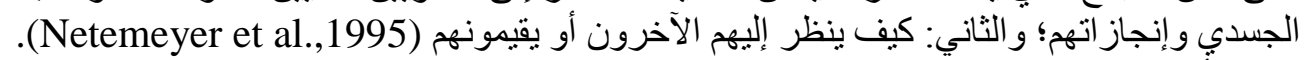

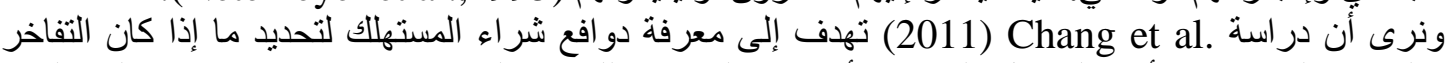

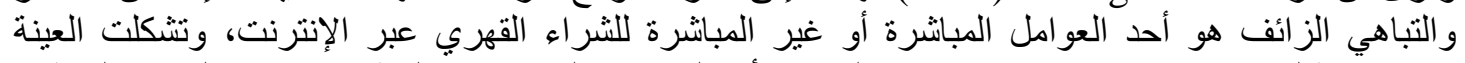

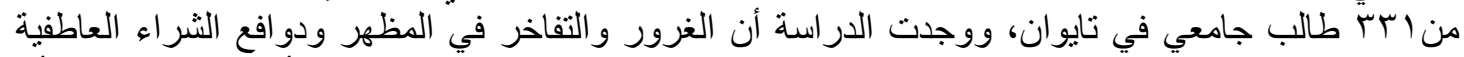

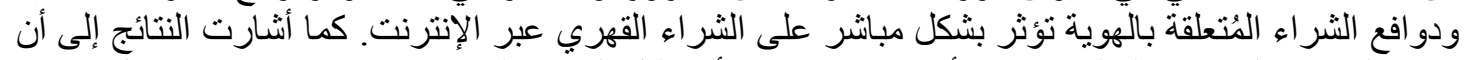

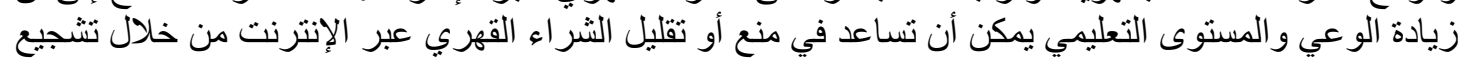




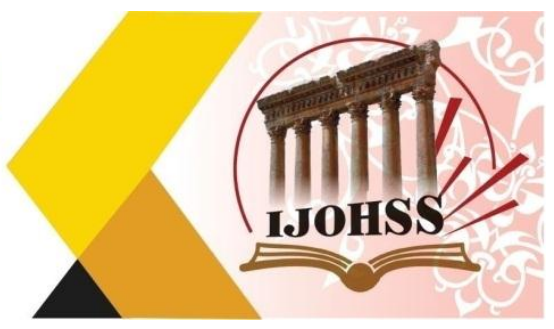

الأفر اد على تطوير موقف نقدي تجاه القيم المادية والرسائل التي يوفر ها الثر اء عبر الإنترنت. وبناء على نتائج

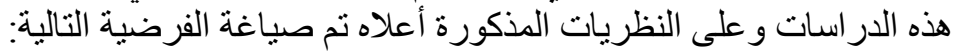

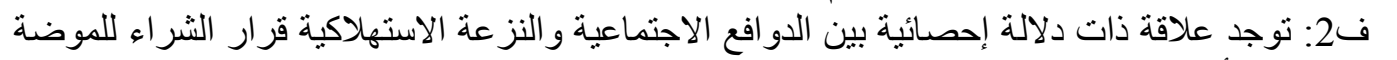
السريعة لاى المر أة السعودية. o

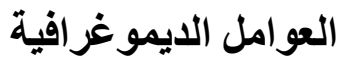

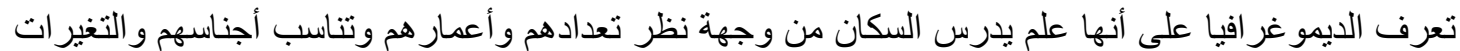

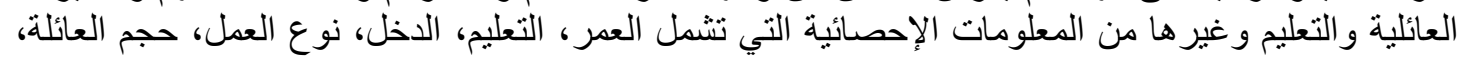

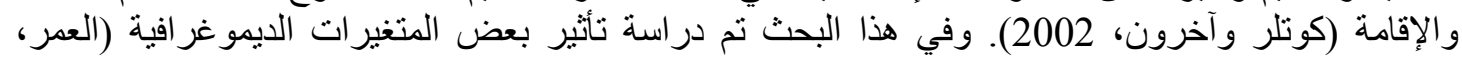

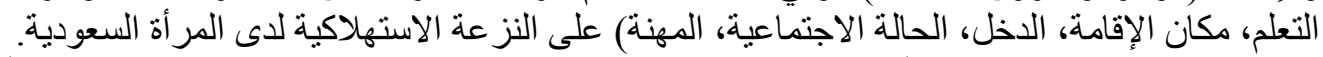

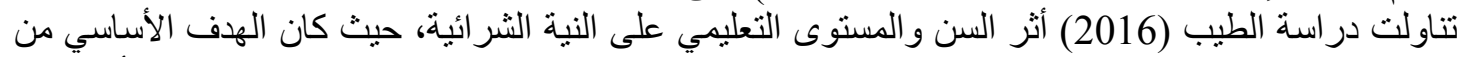

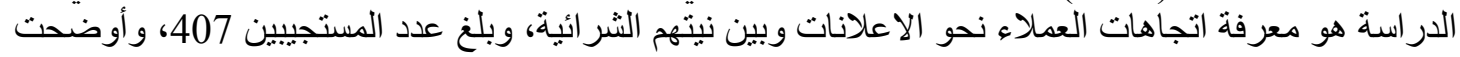

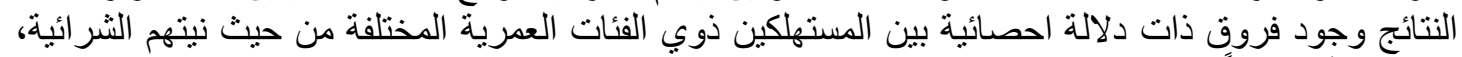
لصالح الأكبر سناً، كما تبين انه لا توجد فروق ذاتية ذات دلالة الحصائية بين المستهلكين ذوي المستويات التعليمية التئية

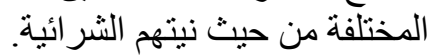

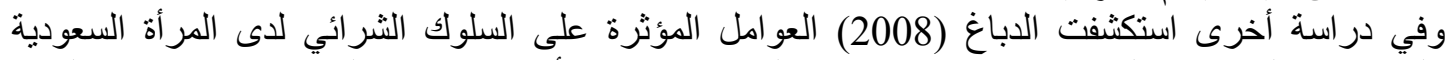

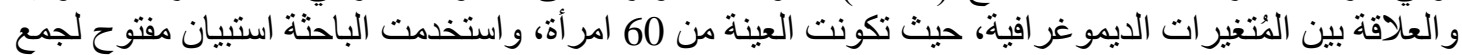

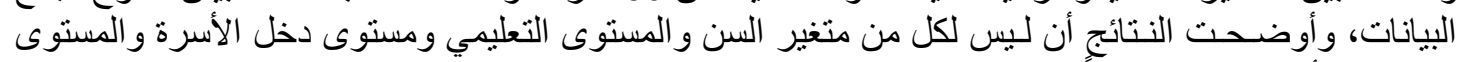

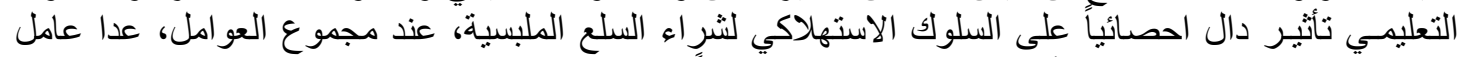

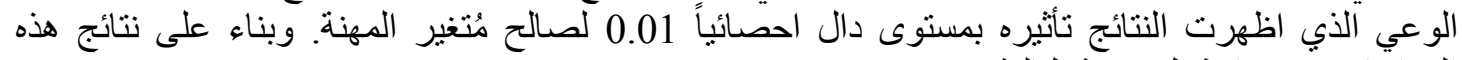
الدراسات تم صياغة الفرضية التالية:

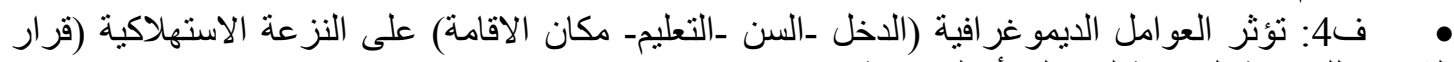
الثر اء) للموضة السريعة لاى المر أة السعودية.

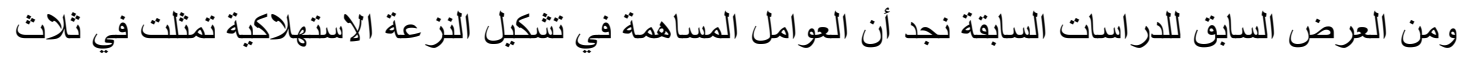

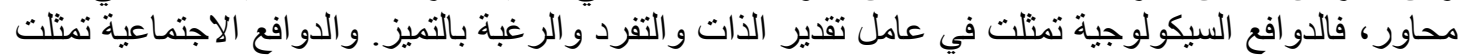

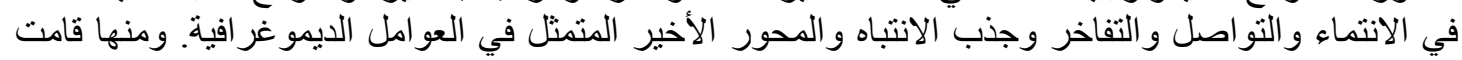
البآحثة برسم هيكلة فرضيات الأندر اسة انظر شكل رقم (2). 

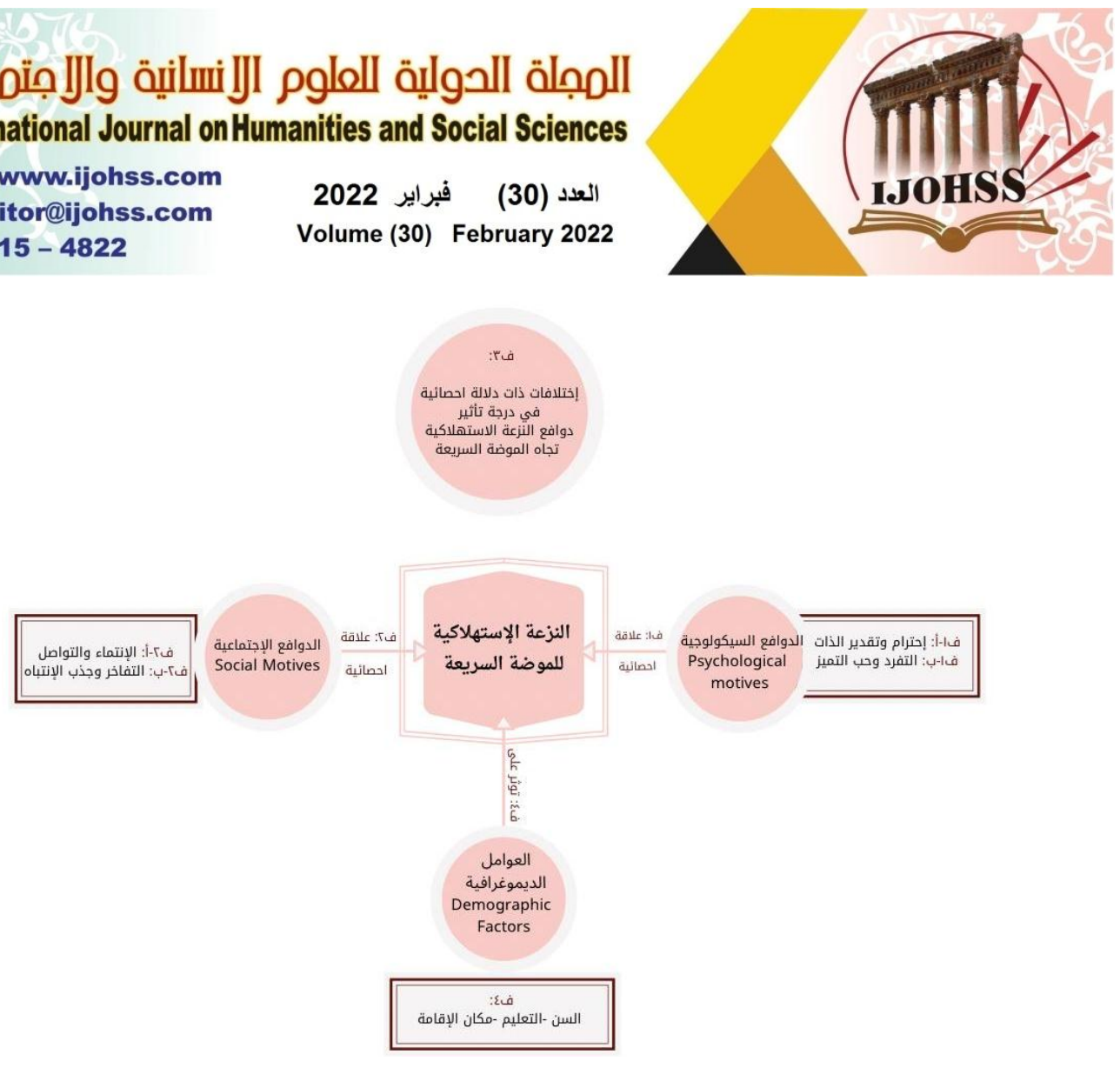

شكل (2) هيكية الفرضيات

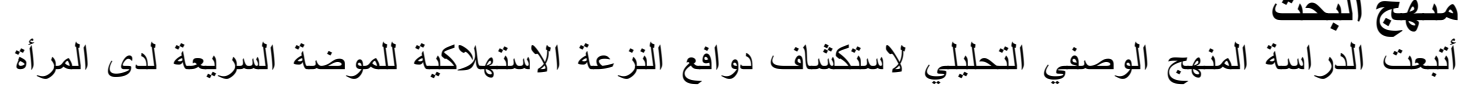

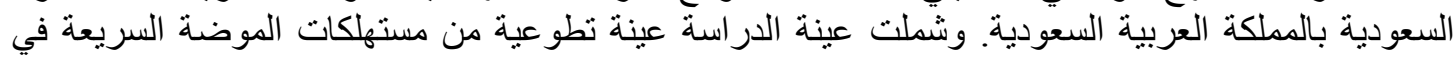

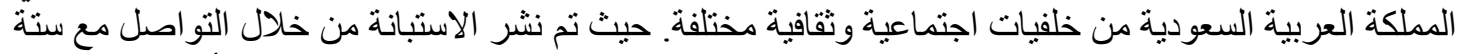

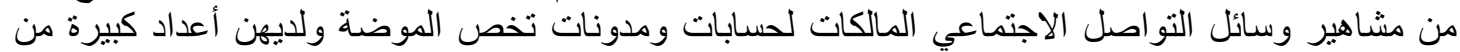

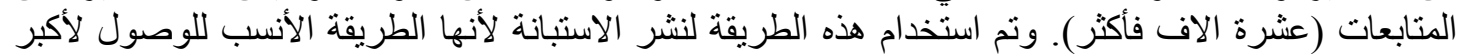
عدد ممكن من مجتمع البحث (مستهاكلكات الموضة السترة السريعة في المملكة).

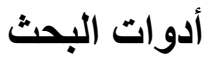

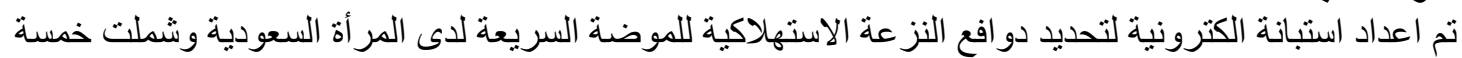

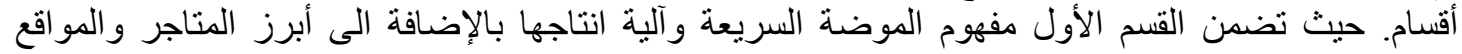

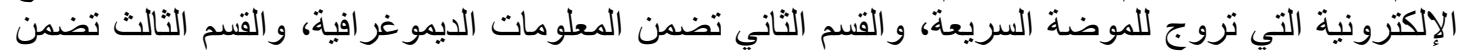

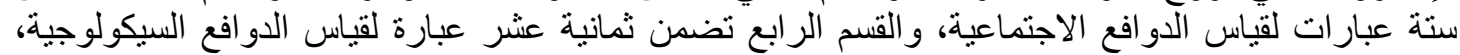
و القسم الأخير تضمن أربع عبار ات لقياس نية اتخاذ قرار الثراء الثراء.

\section{التحقق من ثبات وصدق أدوات البحث}

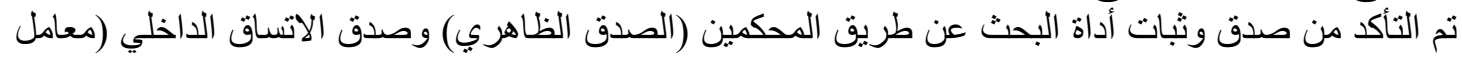

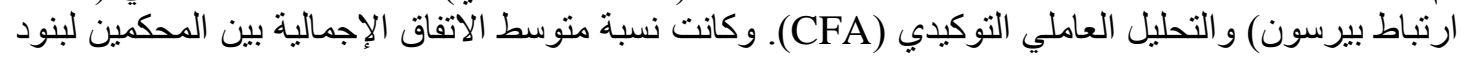

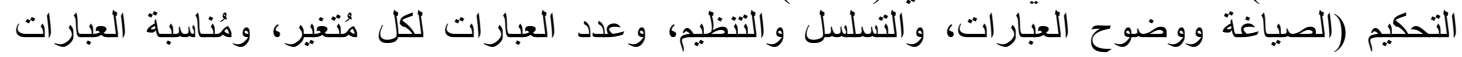

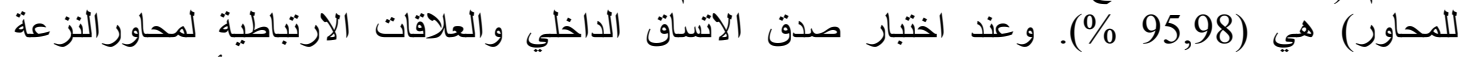

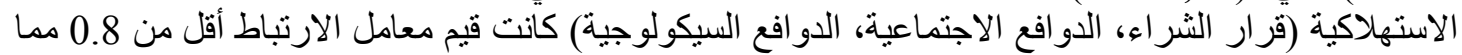

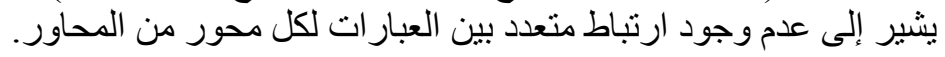




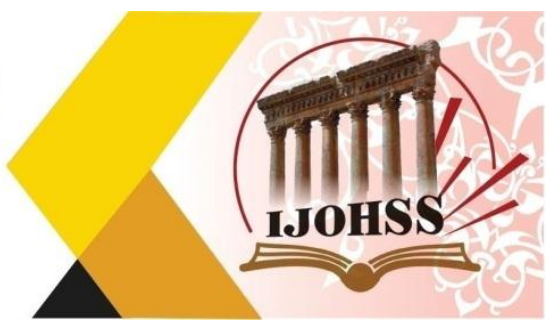

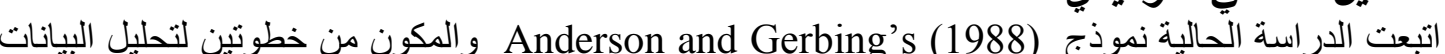

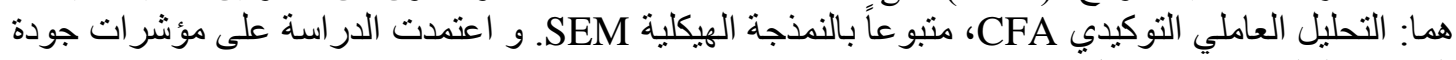
جدول (1) مؤشرات جودة المطابقة

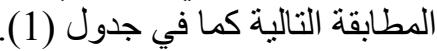

\begin{tabular}{|c|c|}
\hline القيمة الافتر اضية Virtual values & المؤشر Indicator \\
\hline كلما كانت صغيرة & قيمة مربع كاي Chi-S \\
\hline أقل من 4 & مربع كاي/درجات الحرية \\
\hline أكبر من 0,9 & GFI مؤشر جودة التطابق \\
\hline أكبر من 0,9 & معامل توكر لويس TLI \\
\hline أكبر من 0,9 & CFI مؤشر الملاءمة المقارن \\
\hline أقل من 0,09 & جذر منوسط الخطأ التربيعي للتقريب RMSEA \\
\hline
\end{tabular}

1- التحليل العاملي التوكيدي لمحور التزعة الاستهرلاكية

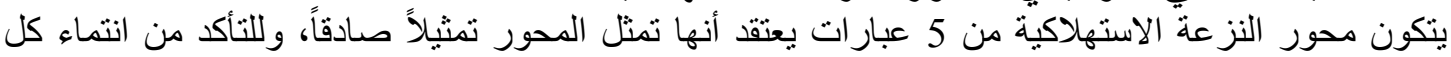

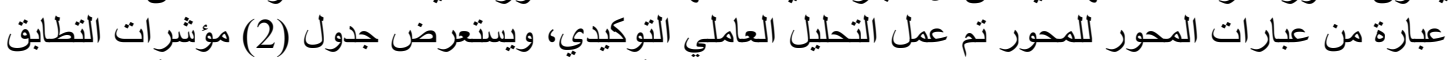

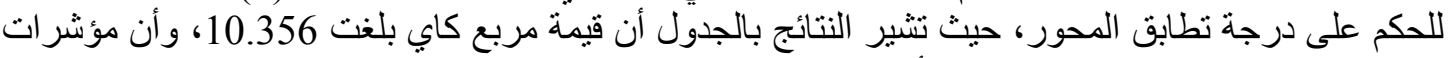

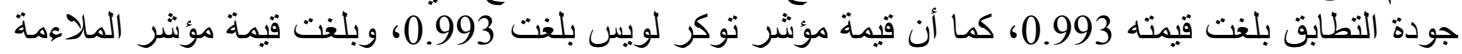

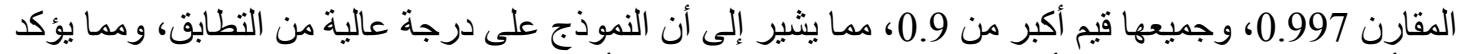
ذللك أن قيمة جذر منوسط الخطأ التقريبي بلغت 0.042 و هي قيمة أقل من أن على 0.08.

جدول (2) مؤشرات التطابق لمحور النزعة الاستهلاكية

\begin{tabular}{|c|c|c|}
\hline $\begin{array}{r}\text { القيمة الحالية } \\
\text { Result }\end{array}$ & $\begin{array}{c}\text { القيمة الافتراضية } \\
\text { Virtual values }\end{array}$ & $\begin{array}{r}\text { المؤشُر } \\
\text { Indicator }\end{array}$ \\
\hline 10.356 & كلما كانت صغيرة & قيمة مربع كاي Chi-S \\
\hline 2.07 & أقل من 4 & مربع كاي/درجات الحرية \\
\hline 0.993 & أكبر من 0.9 & مؤشر جودة التطابق GFI \\
\hline 0.993 & أكبر من 0.9 & معامل توكر لويس TLI \\
\hline 0.997 & أكبر من 0.9 & CFI مؤشر الملاءمة المقارن \\
\hline 0.042 & أقل من 0.08 & جذر منوسط الخطأ التربيعي للتقريب RMSEA \\
\hline
\end{tabular}

2- التحليل العاملي التوكيدي لمحور الدوافع الاجتماعية

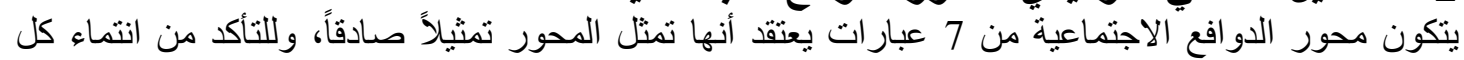

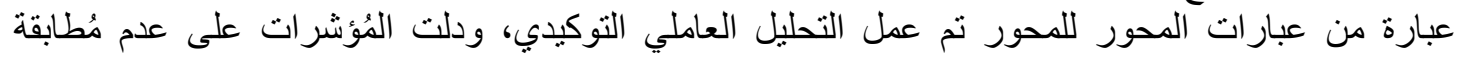

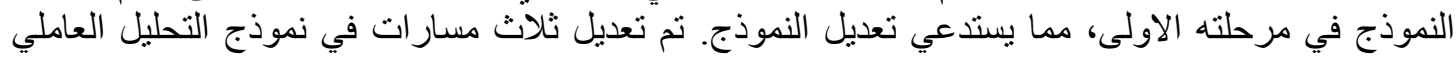

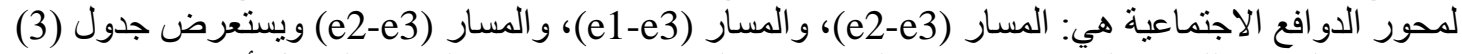

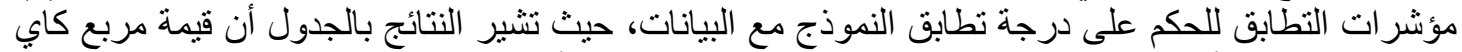

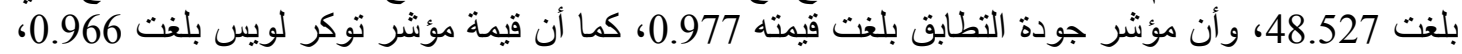

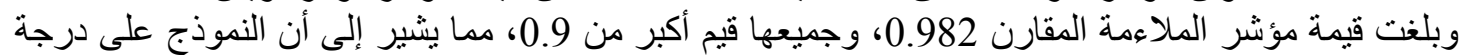
عالية من النطابق، ومما يؤكد ذللك أن قيمة جذر منوسط الخطأ التقريبي بلغت 0.075 ون وهي قيمة أقل من 


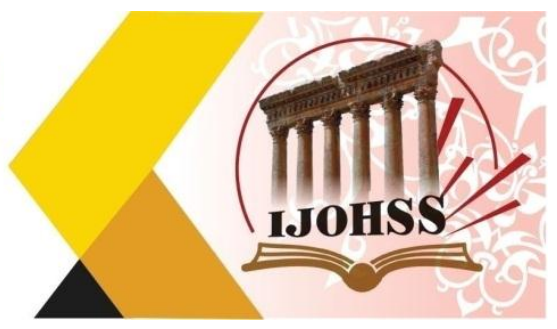

جدول (3) مؤشرات التطابق لمحور الدو افع الاجتماعية بعد التعديل

\begin{tabular}{|c|c|c|}
\hline $\begin{array}{r}\text { القيمة الحالية } \\
\text { Result }\end{array}$ & $\begin{array}{r}\text { القيمة الافتراضية } \\
\text { Virtual values }\end{array}$ & $\begin{array}{r}\text { المؤشر } \\
\text { Indicator }\end{array}$ \\
\hline 48.527 & كلما كانت صغيرة & قيمة مربع كاي Chi-S \\
\hline 4.14 & أقل من 4 & مربع كاب/درجات الحرية \\
\hline 0.977 & أكبر من 0.9 & GFI مؤشر جودة التطابق \\
\hline 0.966 & أكبر من 0.9 & معامل توكر لويس TLI \\
\hline 0.982 & أكبر من 0.9 & مؤشر الملاءمة المقارن CFI \\
\hline 0.075 & أقل من 0.08 & جذر متوسط الخطأ التربيعي للتقريب RMSEA \\
\hline
\end{tabular}

3- التحليل العاملي التوكيدي لمحور الدوافع السيكولوجية.

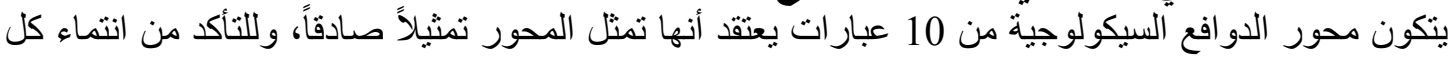

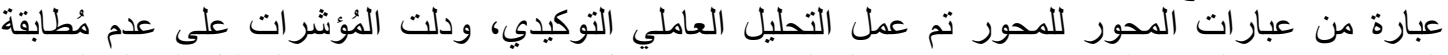

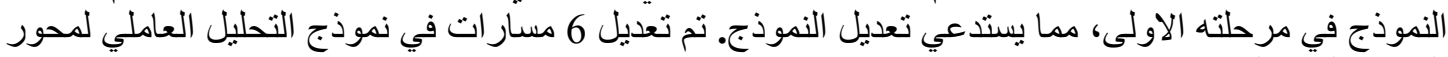

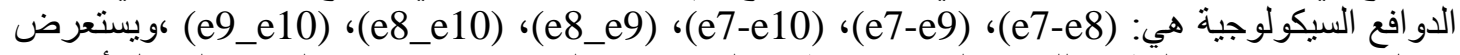

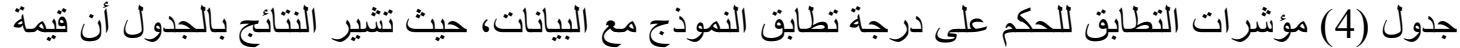

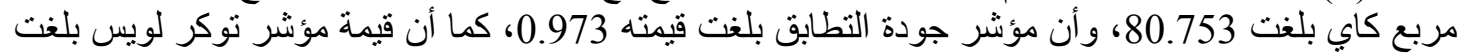

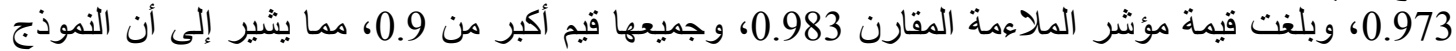

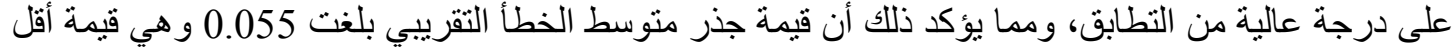

جدول (4) مؤشرات التطابق لمحور الدوافع السيكولوجية بعد التعديل

من 0.08.

\begin{tabular}{|c|c|c|}
\hline $\begin{array}{r}\text { القيمة الحالية } \\
\text { Result }\end{array}$ & القيمة الافتراضية & $\begin{array}{r}\text { المؤشر } \\
\text { Indicator }\end{array}$ \\
\hline 80.753 & كلما كانت صغيرة & قيمة مربع كاي Chi-S \\
\hline 2.785 & أقل من 4 & مربع كاي/درجات الحرية \\
\hline 0.973 & أكبر من 0.9 & مؤشر جودة التطابق GFI \\
\hline 0.973 & أكبر من 0.9 & معامل توكر لويس TLI \\
\hline 0.983 & أكبر من 0.9 & CFI مؤشر الملاءمة المقارن \\
\hline 0.055 & أقل من 0.08 & جذر متوسط الخطأ التربيعي للتقريب RMSEA \\
\hline
\end{tabular}

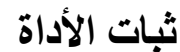

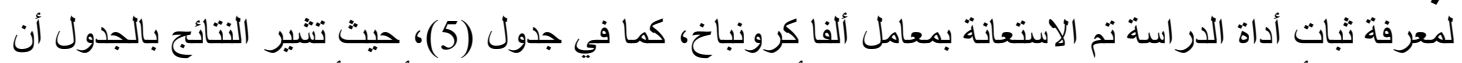

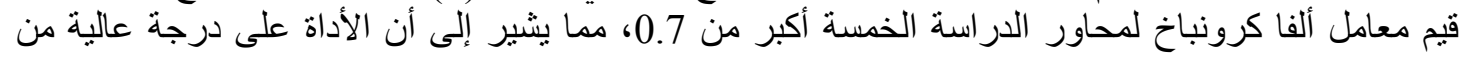

جدول (5) معامل ألفا كرونباخ للحكم على ثبات الأداة

\begin{tabular}{|c|c|c|}
\hline معامل ألفا كرونباخ & عدد العبارات & المحور \\
\hline 0.872 & 5 & النزعة الاستهلاكية (قرار الشراء) \\
\hline 0.879 & 7 & الدو افع الاجتماعية \\
\hline 0.876 & 10 & الدو افع السيكولوجية \\
\hline
\end{tabular}




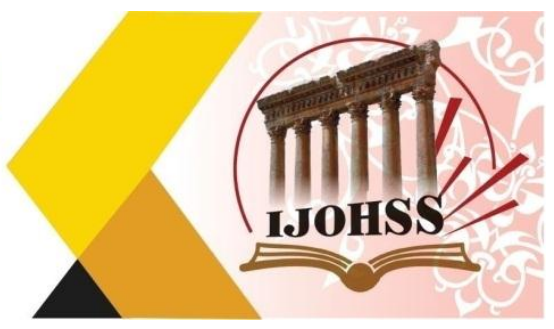

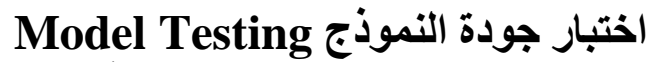

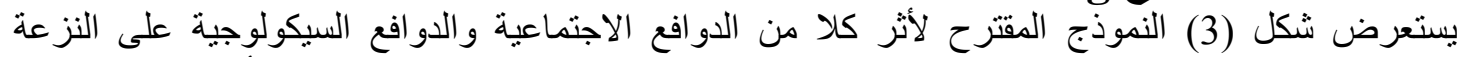

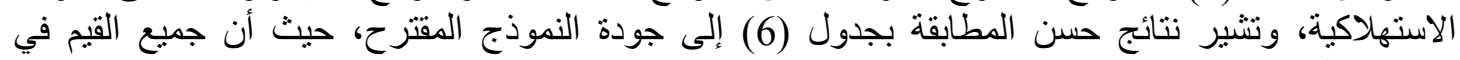

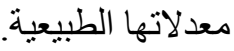

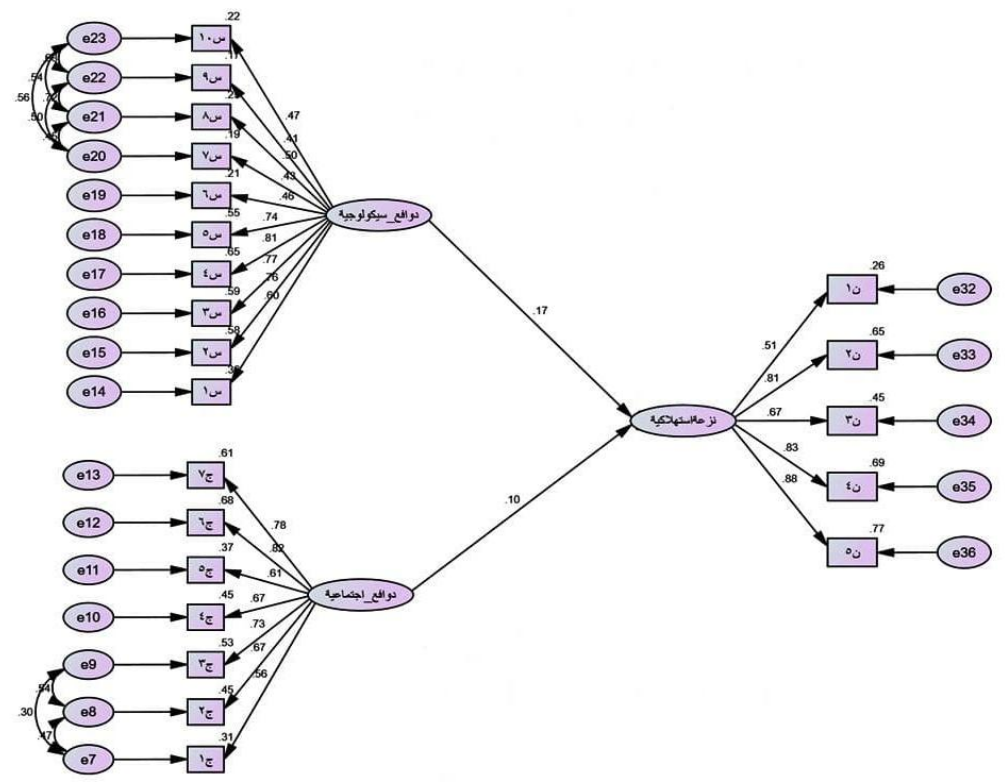

شكل (3) النموذج المقترح في صورته الأولى

جدول (6) مؤشرات جودة النموذج المقترح

\begin{tabular}{|c|c|c|}
\hline $\begin{array}{r}\text { القيمة الحالية } \\
\text { Result }\end{array}$ & $\begin{array}{c}\text { القيمة الافتر اضية } \\
\text { Virtual values }\end{array}$ & $\begin{array}{r}\text { المؤشر } \\
\text { Indicator }\end{array}$ \\
\hline 0.9 & أكبر من 0.9 & مؤشر جودة النطابق GFI \\
\hline 0.93 & أكبر من 0.9 & معامل توكر لويس TLI \\
\hline 0.92 & أكبر من 0.9 & CFI مؤشر الملاءمة المقارن \\
\hline 0.067 & أقل من 0.08 & جذر متوسط الخطأ التربيعي للتقريبRSEA \\
\hline
\end{tabular}

نتائج البحث ومناقشتها

التحليل الوصفي Descriptive analysis

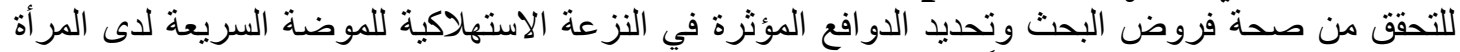

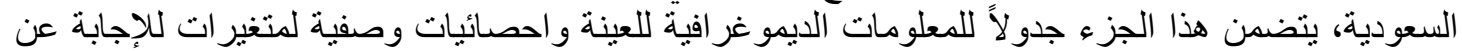
تساؤلات البحث.

التحليل الايموغر افي للعينة Demographic Profile of Sample

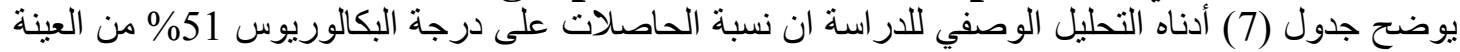

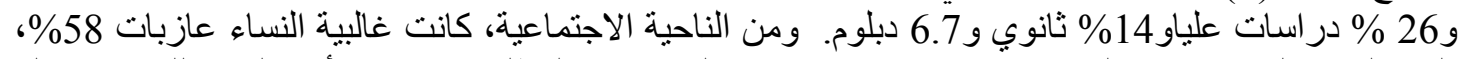

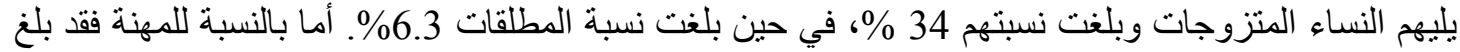
عدد الطالبات 36\% وتلتها نسبة العاطلات عن العمل حيث بلغت نسبتهم 34\%، وبلغ عدد الموظفات 12\% بلغ الغ 


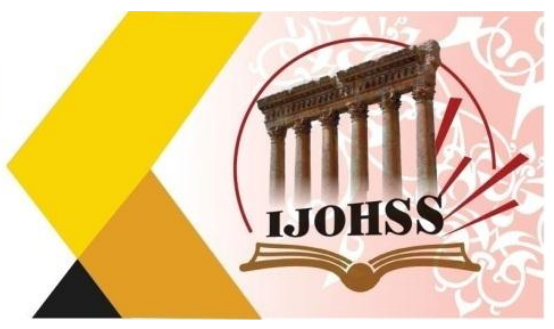

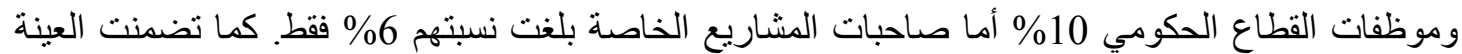

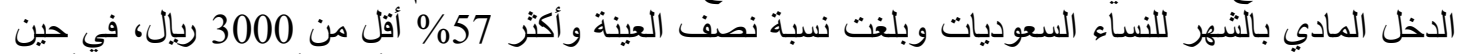

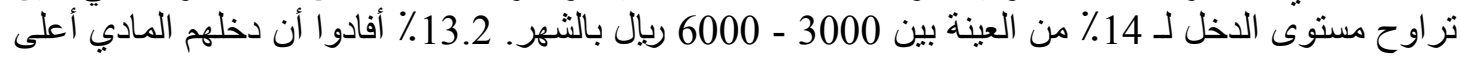

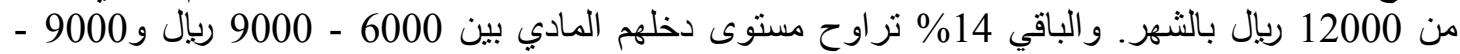
جدول (7) الجدول التكراري للمتغيرات الايموغرافية لعينة البحث 12000 بالثهر.

\begin{tabular}{|c|c|c|c|c|}
\hline النسبة التراكمية & $\begin{array}{r}\text { النسبة } \\
\text { Percent }\end{array}$ & $\begin{array}{r}\text { التكرارات } \\
\text { Frequency }\end{array}$ & & $\begin{array}{r}\text { المتغيرات } \\
\text { Variables }\end{array}$ \\
\hline \multirow{5}{*}{$\begin{array}{r}42.7 \\
74.2 \\
86.3 \\
100.0\end{array}$} & 42.7 & 256 & $25-18$ & \multirow{5}{*}{ 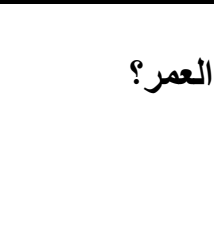 } \\
\hline & 31.5 & 189 & $35-26$ & \\
\hline & 12.2 & 73 & $45-36$ & \\
\hline & 13.7 & 82 & 16 4وفوق & \\
\hline & 100.0 & 600 & المجموع & \\
\hline \multirow{3}{*}{$\begin{array}{r}65.2 \\
100.0\end{array}$} & 65.2 & 391 & مدينة & \multirow{3}{*}{ مكان الاقامةت؟ } \\
\hline & 34.8 & 209 & محافظة & \\
\hline & 100.0 & 600 & المجموع & \\
\hline \multirow{7}{*}{$\begin{array}{r}0.7 \\
1.7 \\
16.2 \\
22.8 \\
74.0 \\
100.0\end{array}$} & 0.7 & 4 & أقل من متوسط & \multirow{7}{*}{ التعليمي؟ } \\
\hline & 1.0 & 6 & متوسط & \\
\hline & 14.5 & 87 & ثانوي & \\
\hline & 6.7 & 40 & 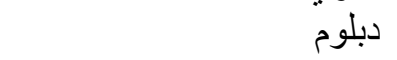 & \\
\hline & 51.2 & 307 & جامعي & \\
\hline & 26.0 & 156 & در اساتّ عليا & \\
\hline & 100.0 & 600 & المجموع & \\
\hline \multirow{5}{*}{$\begin{array}{r}58.0 \\
92.5 \\
98.8 \\
100.0\end{array}$} & 58.0 & 348 & عزباء & \multirow{5}{*}{ الاجتماعية؟ } \\
\hline & 34.5 & 207 & منزوجة & \\
\hline & 6.3 & 38 & مطلقة & \\
\hline & 1.2 & 7 & أرملة & \\
\hline & 100.0 & 600 & 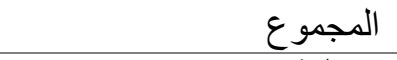 & \\
\hline \multirow{6}{*}{$\begin{array}{r}12.3 \\
22.7 \\
28.7 \\
65.5 \\
100.0\end{array}$} & 12.3 & 74 & موظفة & \multirow[t]{6}{*}{ المهزة؟ } \\
\hline & 10.3 & 62 & وظيفة حكومية & \\
\hline & 6.0 & 36 & صاحبة مشروع خاص & \\
\hline & 36.8 & 221 & طالبة & \\
\hline & 34.5 & 207 & غير موظفة & \\
\hline & 100.0 & 600 & المجموع & \\
\hline \multirow{6}{*}{$\begin{array}{r}57.7 \\
72.5 \\
79.7 \\
86.8 \\
100.0\end{array}$} & 57.7 & 346 & (3000 SAR) & \multirow{6}{*}{ بالشهر؟؟ الاخل } \\
\hline & 14.8 & 89 & 6000 SAR) - (3000 من & \\
\hline & 7.2 & 43 & 9000 SAR) - (6000 من & \\
\hline & 7.2 & 43 & من (9000-12000 SAR) & \\
\hline & 13.2 & 79 & اكثر من (12000 SAR) & \\
\hline & 100.0 & 600 & المجموع & \\
\hline
\end{tabular}




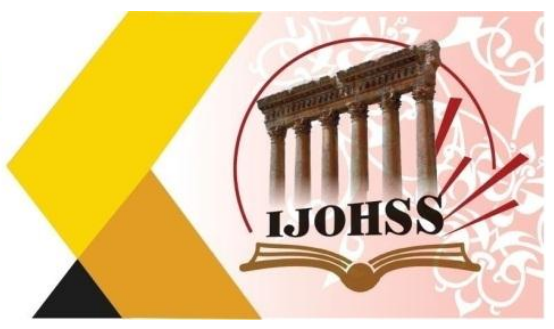

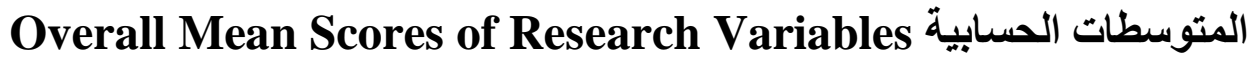

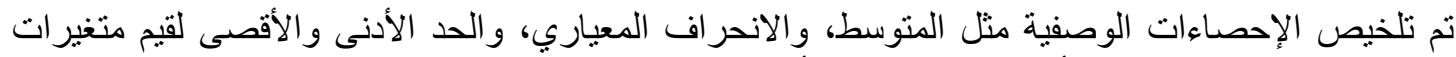

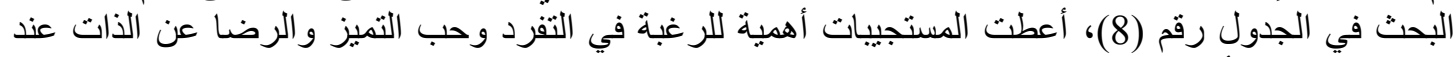

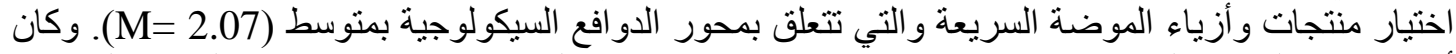

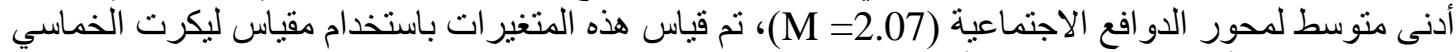

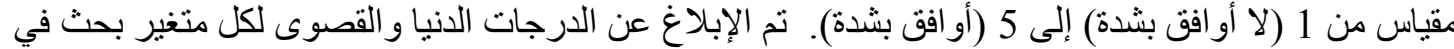
جلول (8) المتوسطات الحسابية لمتغيرات البحث

\begin{tabular}{|c|c|c|c|c|c|}
\hline 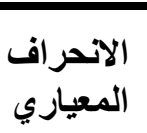 & الحسابي & 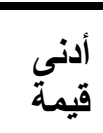 & 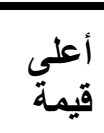 & Items (العناصر) & $\begin{array}{c}\text { المتغيرات } \\
\text { Variables }\end{array}$ \\
\hline 1.09 & 2.92 & 0.80 & 5.00 & المتوسط الكلي لمحور قرار الثراء & \\
\hline $\begin{array}{l}1.28 \\
1.30 \\
1.33\end{array}$ & $\begin{array}{l}2.38 \\
3.19 \\
2.61\end{array}$ & $\begin{array}{l}0.00 \\
1.00 \\
1.00\end{array}$ & $\begin{array}{l}5.00 \\
5.00 \\
5.00\end{array}$ & 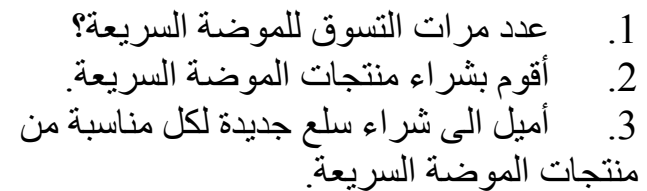 & قرار الثراء \\
\hline 1.38 & 3.21 & 1.00 & 5.00 & 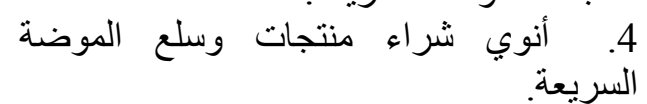 & Decision \\
\hline 1.44 & 3.20 & 1.00 & 5.00 & 5. كانها تلبي ر أميل الى شر اء منتجات الموضة السريعة & \\
\hline 0.94 & 2.07 & 5.00 & 1.00 & المتوسط الكلي لهحور الدو افع الاجتماعية & \\
\hline 1.35 & 2.51 & 5.00 & 1.00 & 1. منتجات وأزياء بقبول الموضة السرين ليعة. عند استخدامي & \\
\hline 1.22 & 2.03 & 5.00 & 1.00 & 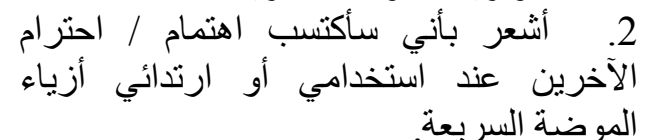 & \\
\hline 1.29 & 2.19 & 5.00 & 1.00 & 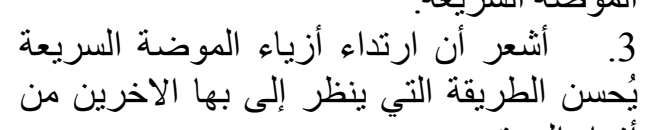 & الاجتماعية \\
\hline 1.21 & 1.99 & 5.00 & 1.00 & 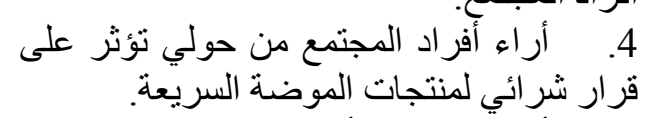 & $\begin{array}{r}\text { Social } \\
\text { motivations }\end{array}$ \\
\hline 1.16 & 1.79 & 5.00 & 1.00 & 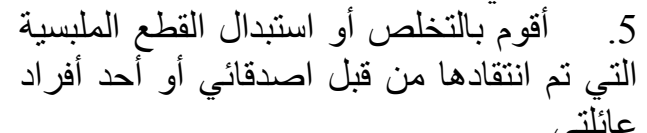 & \\
\hline 1.09 & 1.73 & 5.00 & 1.00 & 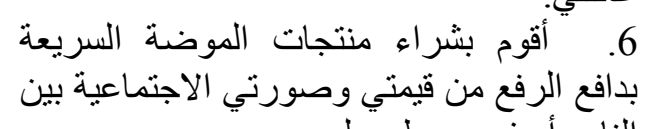 & \\
\hline 1.34 & 2.22 & 5.00 & 1.00 & 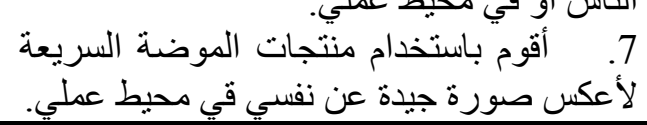 & \\
\hline
\end{tabular}




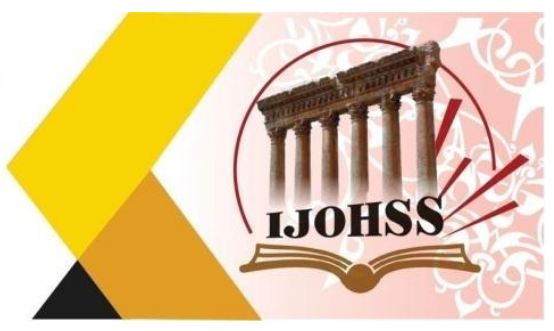

المتوسط الكلي لمحور الدوافع السيكولوجية $\quad 2.00 \quad 5.00 \quad 1.00 \quad 52 \quad 0.92$

1. الموضة السريعة الغير عادية كوسيلة لخلق أنقاء صورة شخصية أكثر تميزً.

2.

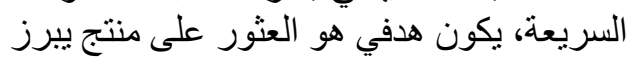

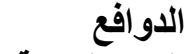

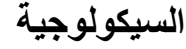

Psychologic تفردي.

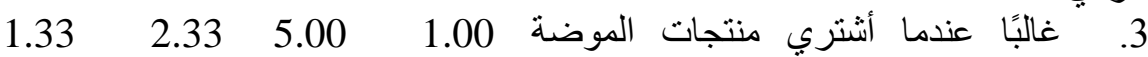
السريعة أفكر في كيفية استخدامها لتنكيل نمط

motivations

4. أقوم بدمج السلع ومنتجات الموضة $1.00 \quad 5.00 \quad 2.88 \quad 1.42$

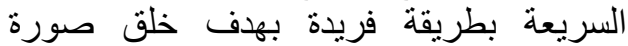
شخصية لا يمكن تقليدها.

5. أحاول العثور على موديلات ملفتة للنظر.

6. علامات الازياء التجارية التي يشتريها عامة

7. أشعر بالرضا عن نفسي عند ارتدائي $1.00 \quad 2.89 \quad 5.00 \quad 23$ أزياء الموضنة السريعة.

8. منتجات الموضةً السريعة.

9. ارتدائي منتجات الموضة السريعة.

10. أنظّر الى نفسي بصورة إيجابية عند $1.00 \quad 5.00 \quad 2.61 \quad 1.37 \quad 20$ ارتدائي منتجات الموضئة السريعة.

نموذج التحليل المساري Structural Equation Model النمذجة البنائية (Structural model tests) هي أحد الأساليب المستخدمة للتحقق من مقبولية أو منطقية نموذج المبرجي

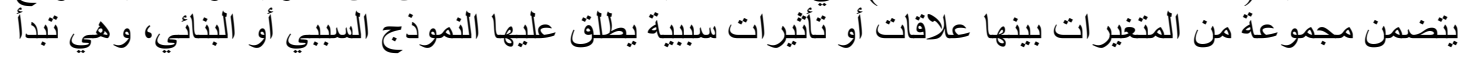

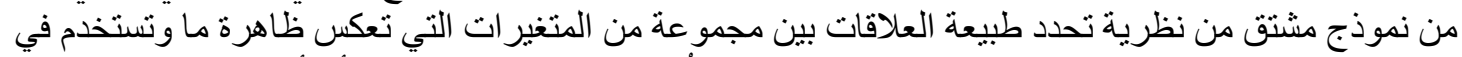

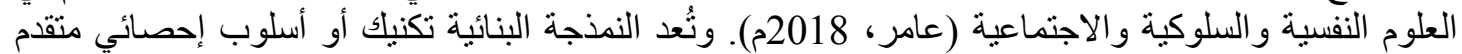

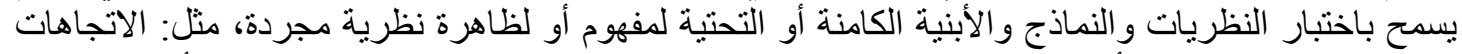

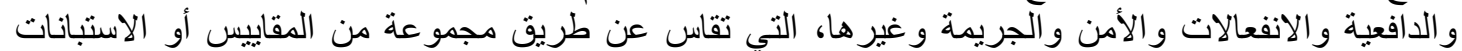

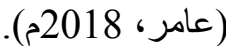
نتائج الفرض الأول والثر والثاني

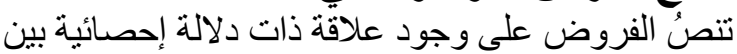

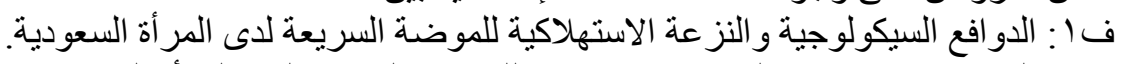

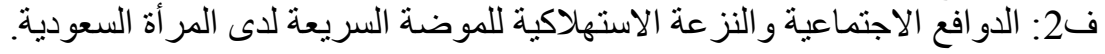


العدد (30) فبراير 2022

Volume (30) February 2022

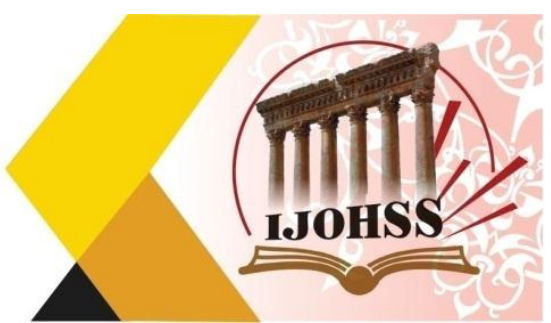

العلاقات الارتباطية بين كل من الدو افع الاجتماعية و الدوافع السيكولوجية، وبين النزعة الاستهلاكية تثير النتائج

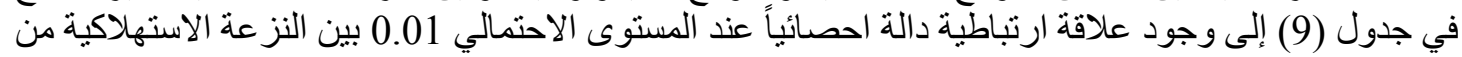

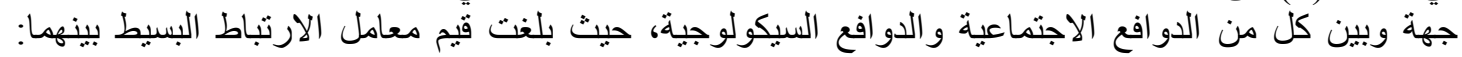

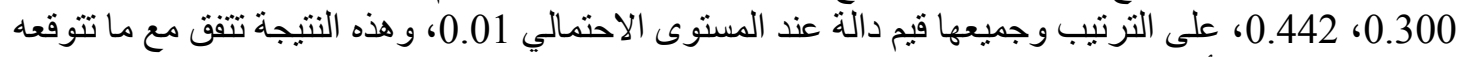
الفروض البحثية الأول و الثناني.

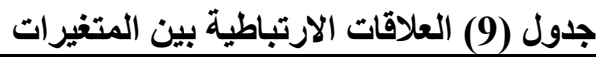

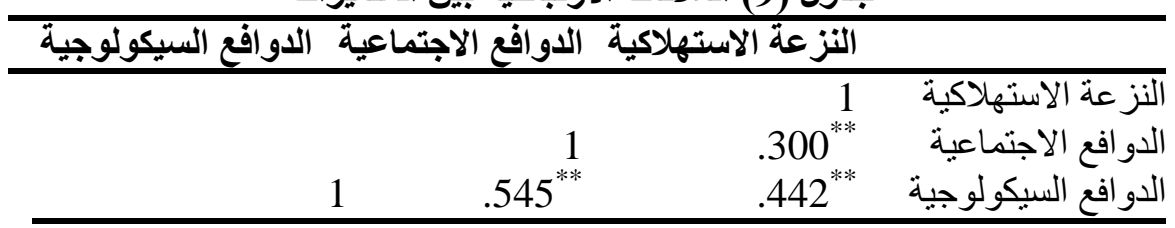

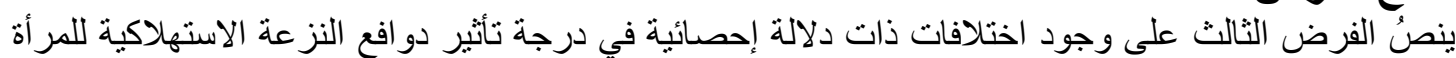

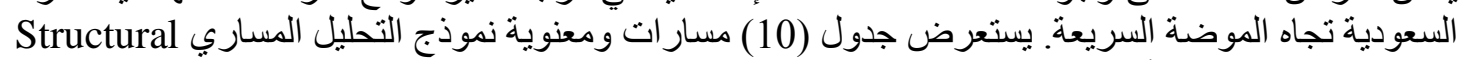

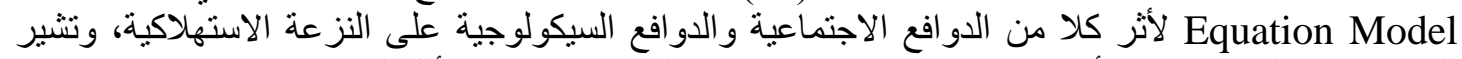

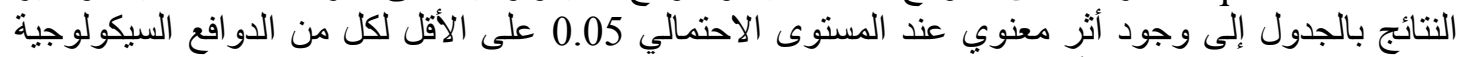

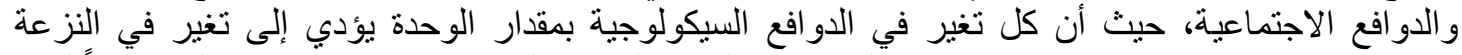

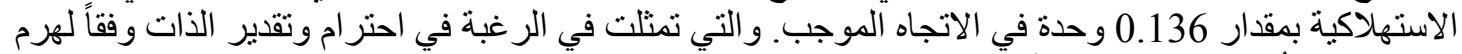

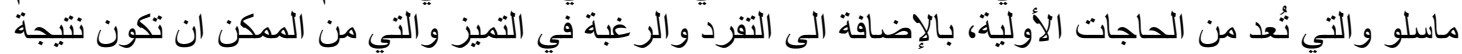

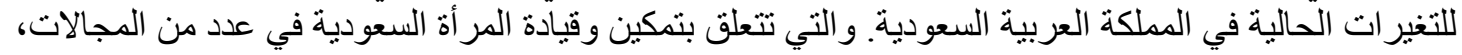

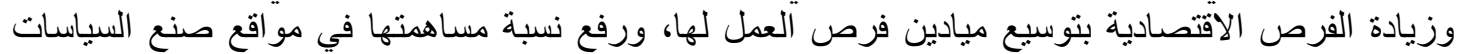

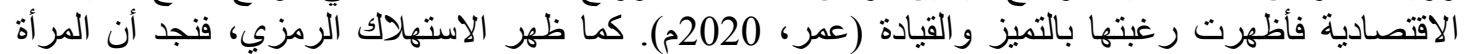

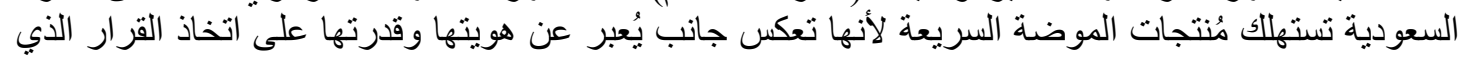

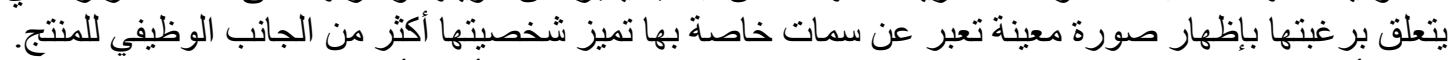

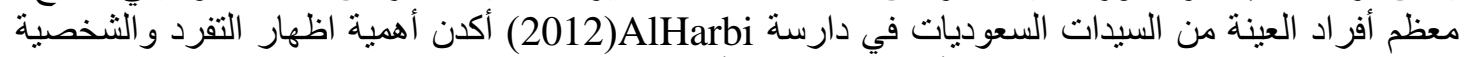

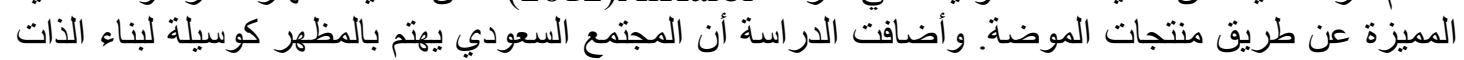

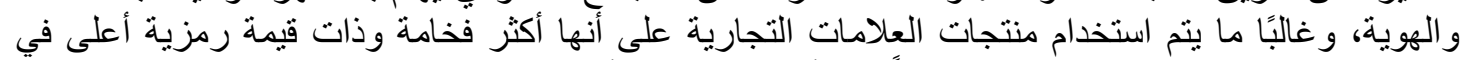

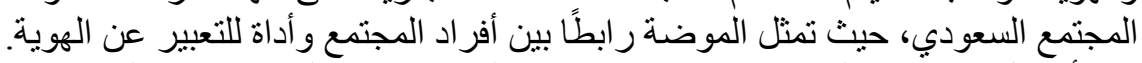

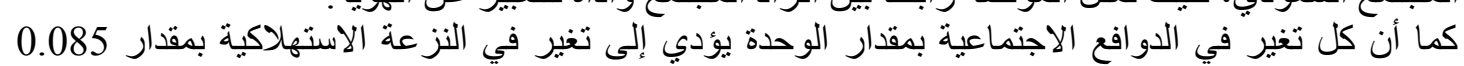

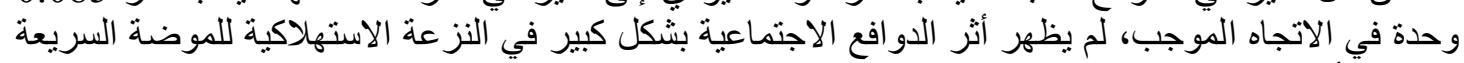

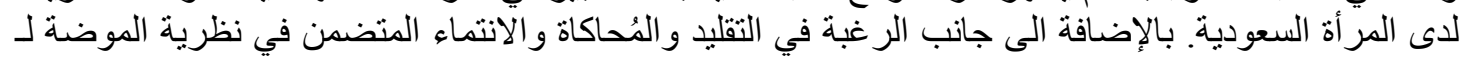
Georg Simmel

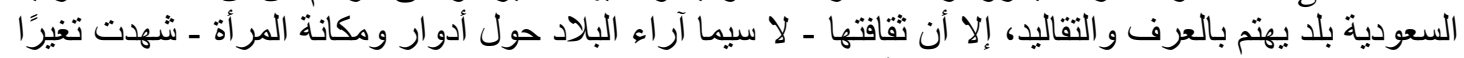

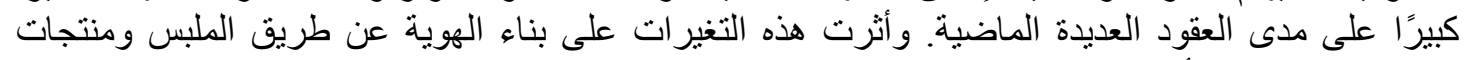

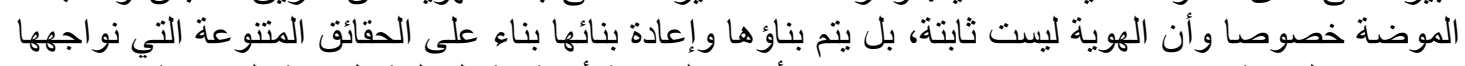

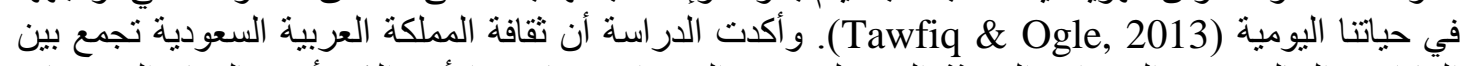

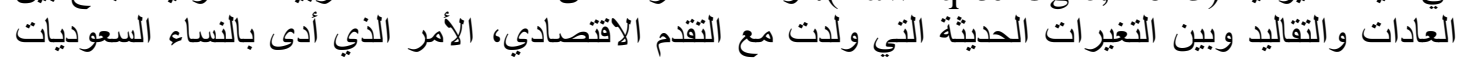

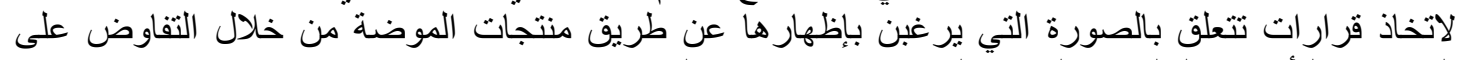
العديد من النتأثير ات التقليدية والحديثة الموجودة في حياتهن اليومية (Tawfiq \& Ogle, 2013). 
العدد (30) مبراير 2022

Volume (30) February 2022

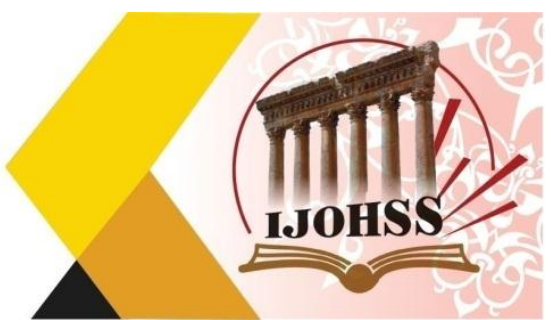

جدول (10) مسارات ومعنوية نموذج تحليل المسار

\begin{tabular}{|c|c|c|c|c|c|c|}
\hline $\begin{array}{r}\text { المعنوية } \\
\text {.Sig }\end{array}$ & $\begin{array}{r}\text { قيمة ت } \\
\text { t-value }\end{array}$ & $\begin{array}{r}\text { الخطأ } \\
\text { Stander } \\
\text { error }\end{array}$ & $\begin{array}{r}\text { التأثير } \\
\text { B beta }\end{array}$ & $\begin{array}{r}\text { المتغير المتأثر } \\
\text { Independent } \\
\text { variables } \\
\end{array}$ & & $\begin{array}{r}\text { المتغير المؤثر } \\
\text { Dependent } \\
\text { variables }\end{array}$ \\
\hline$* * *$ & 3.768 & .036 & .136 & نز عة استهلاكية & $<--$ & دو افع سيكولوجية \\
\hline .018 & 2.358 & .036 & .085 & نز عة استههلاكية & $<--$ & دو افع اجتماعية \\
\hline
\end{tabular}

نتائج الفرض الرابع الريع

يتوقع الفرض الرابع وجود نأثير للعو امل الديمو غر افية (الدخل ـالسن ـالتعليم- السكن) على النزعة التعة الاستهلاكية

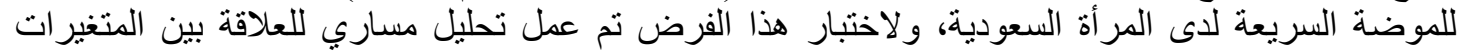

الديمو غر افية والنزعة الاستهلاكية كما في شكل (4).

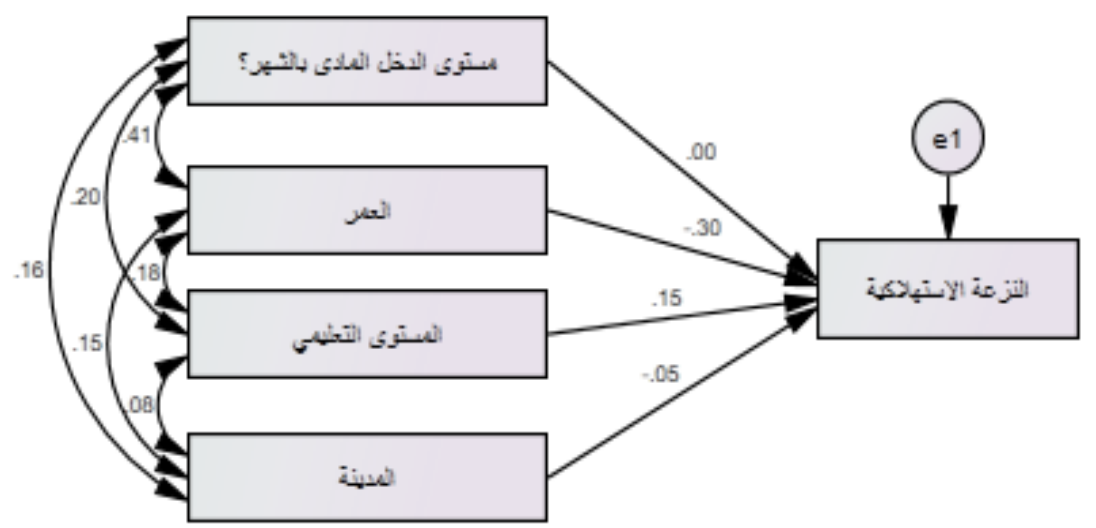

شكل (4) تحليل مساري للعلاقة بين المتغيرات الديموغرافية والنزعة الاستهلاكية

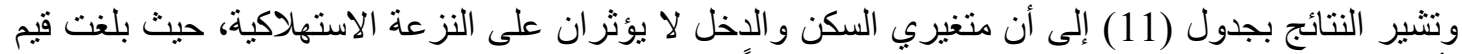

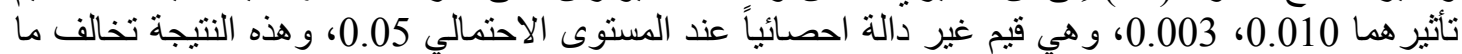

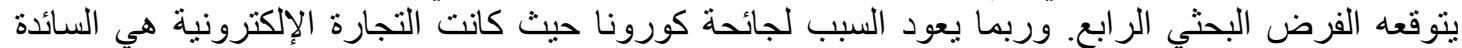

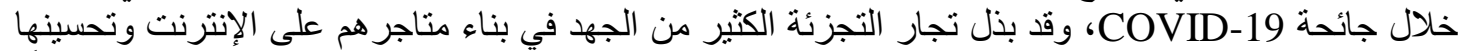

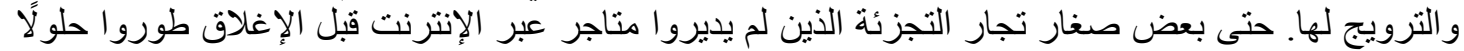

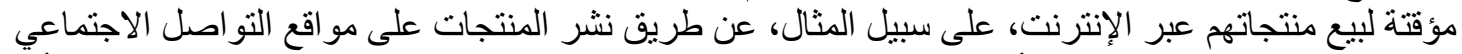

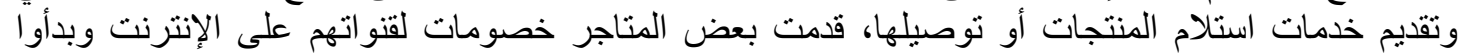

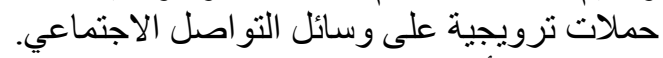

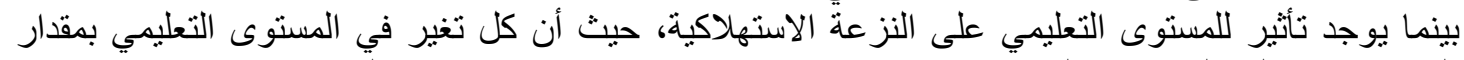

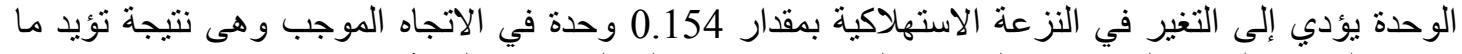

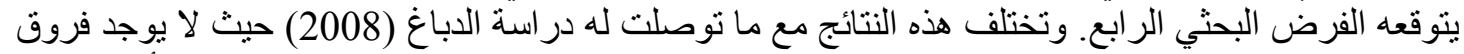

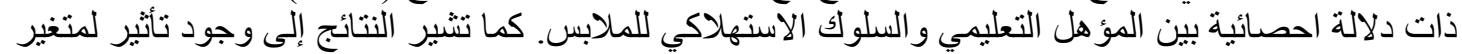

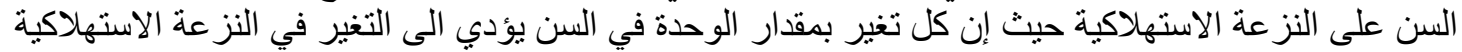

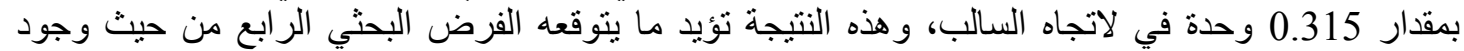

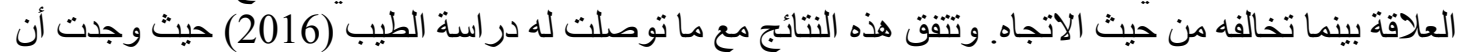

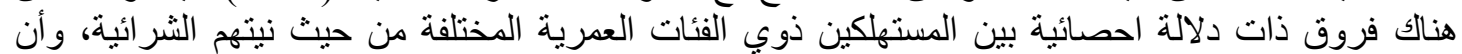

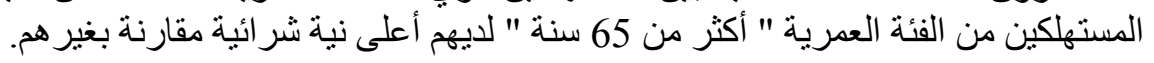


العدد (30) فبراير 2022

ISSN: $2415-4822$

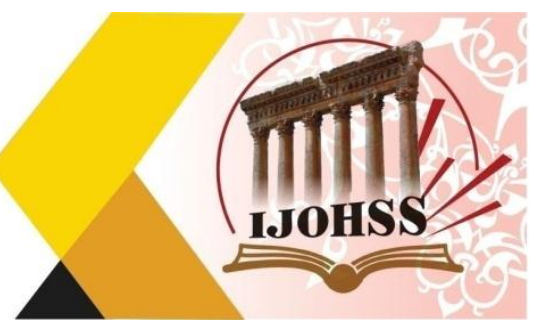

Volume (30) February 2022

جدول (11) مسارات ومعنوية نموذج تحليل المسار

\begin{tabular}{|c|c|c|c|c|c|c|}
\hline المعنوية & $\begin{array}{r}\text { قيمة } \\
\text { t-value }\end{array}$ & $\begin{array}{r}\text { الخطأ } \\
\text { Stander } \\
\text { error }\end{array}$ & التأثير & $\begin{array}{r}\text { المتغير المتأثرز } \\
\text { Independent } \\
\text { variables }\end{array}$ & & $\begin{array}{r}\text { المتفير المؤثر } \\
\text { Dependent } \\
\text { variables }\end{array}$ \\
\hline .238 & -1.180 & .008 & -.010 & النز عة الاستهلاكية & $<---$ & السكن \\
\hline$* * *$ & 3.654 & .042 & .154 & النز عة الاستهلاكية & $<--$ & المستوى التعليمي \\
\hline$* * *$ & -6.989 & .045 & -.315 & النز عة الاستهلاكية & $<--$ & السن \\
\hline .922 & .097 & .033 & .003 & النز عة الاستهلاكية & $<---$ & الدخل ل \\
\hline
\end{tabular}

الاستنتاجات

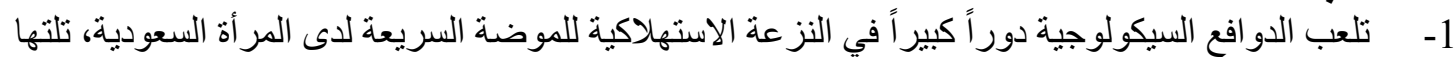

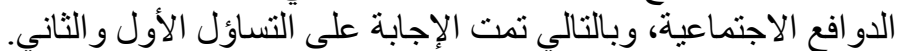

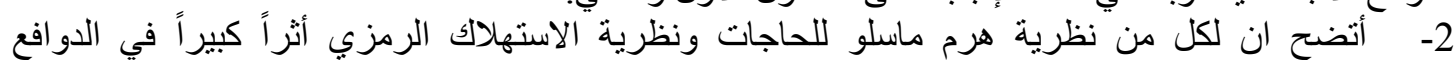

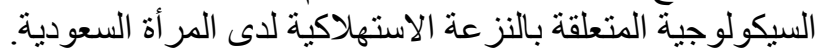

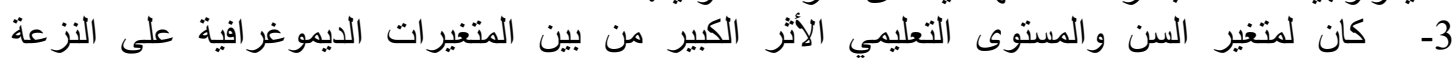
الاستهلاكية للموضة السريعة لدى المر أة السعودية. التوصيات 1- اجر اء دراسات نوعية ومقابلات لفهم أعمق لسلوكيات المستهلك وتأثير التغير ات الحديثة بالمملكة العربية السعودية على نمط استهلاك الازياء وركمانلاتهاتها.

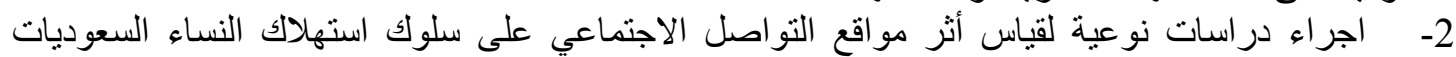
لمازياء ومكملاتها. 3- در اسة الاستهلاك الاخلافي و الموضة المستدامة ومدى و عي المستهلكين بها ومدى تأثثر ذلك في سلوكهم

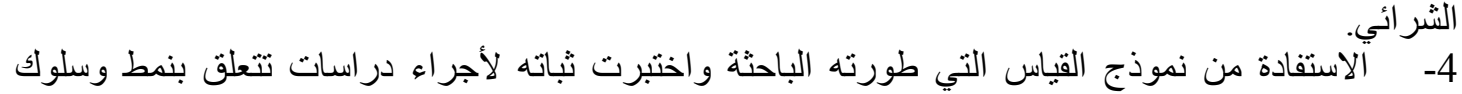

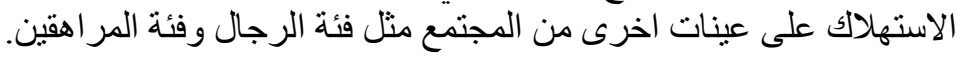

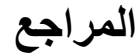

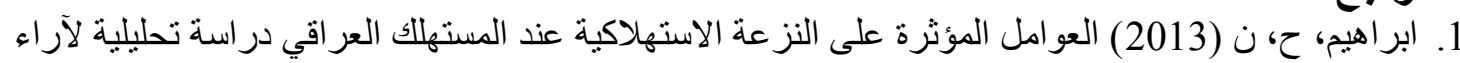

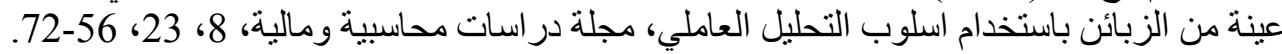

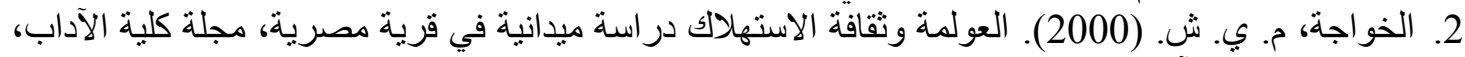

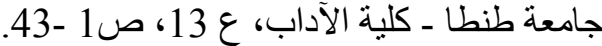

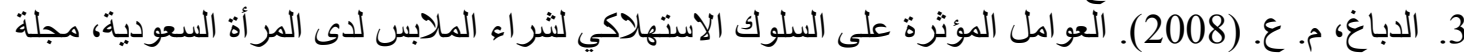

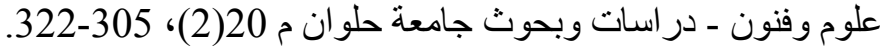

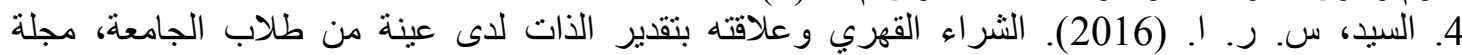

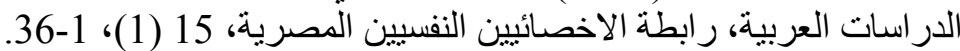

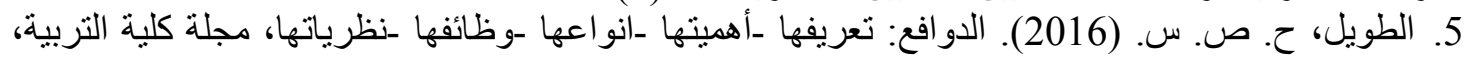

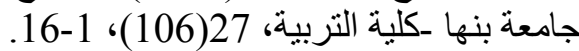

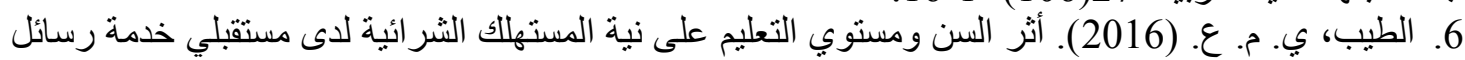

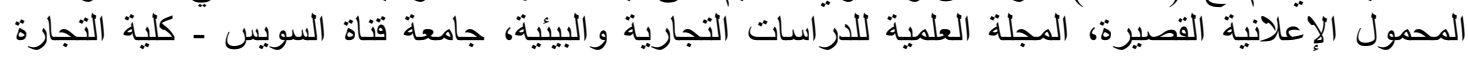
بالإسماعيلية، 7، 485-510. 7. المجني، رانية \& ع عمار، نريمان. (2020). سلوك المستهلك، الجامعة الافتراضية السورية، مؤسسة المشاع الإبداعي، الجمهورية العربية السورية. 
8. صونية، شتوان. (2017). محاضرات في سلوك المستهللك، وزارة التعليم العالي و البحث العلمي، كلية العلوم الاقتصادية و التجارية و علوم التسيير، جامعة محمد الصديق بن بل بحئي.

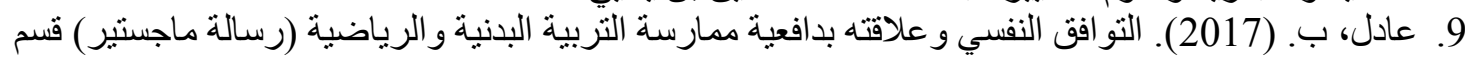

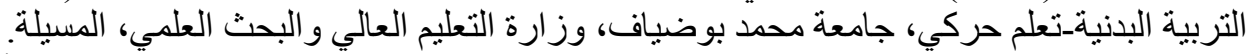

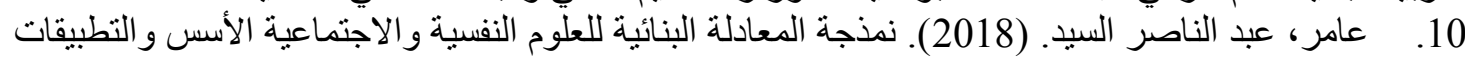

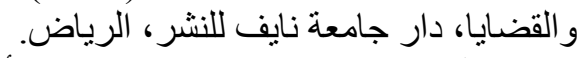

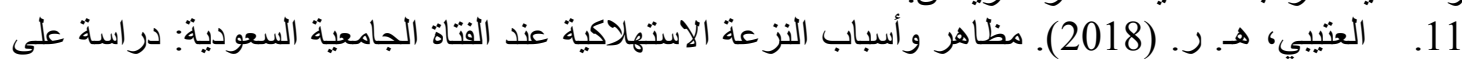

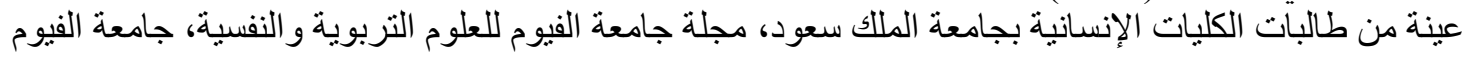

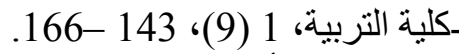
12. عمر، أ. م. (2020). التمكين الاقتصادي للمر أة السعودية: الأبعاد والمعوقات، مجلة جامعة أم القرى

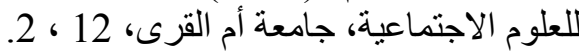

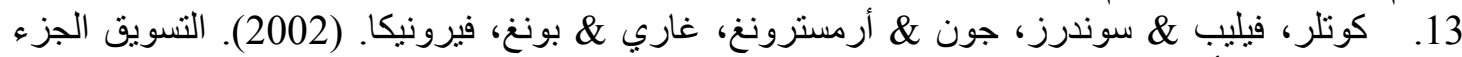

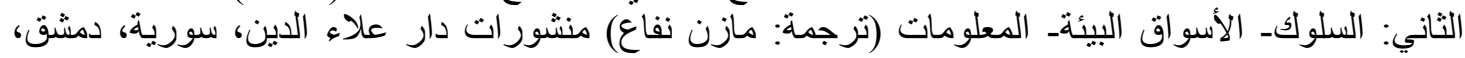

\section{References}

14. Alharbi, W. (2018). An Investigation Info How Women in Saudi Arabia Use Consumption of Fashion to Construct Their Self Image and Social Identity: A Comparison with British Women and Possible Implications on Marketing Management, Social Sciences Arab Journal, The Arab Foundation for Scientific Consultation and Human Resource Development, 14 (5), 2-24.

15. Arnold, M. J. \& Reynolds, K. E. (2003). Hedonic shopping motivations, Journal of Retailing, 79 (2), 77-95.

16. Barnes, L., \& Lea-Greenwood, G. (2006). Fast fashioning the supply chain: shaping the research agenda. Journal of Fashion Marketing and Management: An International Journal, 10 (3), 259-271.

17. Benvenuto, S. (2000). Fashion: Georg Simmel. J. Artif. Soc. Soc. Simul., 3.

18. Bertrandias, L., \& Goldsmith, R.E. (2006). Some psychological motivations for fashion opinion leadership and fashion opinion seeking, Journal of Fashion Marketing and Management, 10 (1), 25-40.

19. Chang, W., Lu, L., Lin, H.S., \& Chang, K. (2011). Mediating effect of buying motives between physical vanity and online compulsive buying. African Journal of Business Management, 5, 3289-3296.

20. Choi, T. (2014). Fast Fashion Systems Theories and Applications, Leiden, The Netherlands, CRC Press/Balkem .

21. Diddi, S. (2014). Understanding ethical consumption decisions: The role of values, attitudes and expectations in the apparel purchasing context. (Doctoral dissertation). DOCTOR OF PHILOSOPHY in Apparel, Merchandising and Design, Iowa State University Ames, Iowa.

22. Douglas, M., Isherwood, B. (1996) The World of Goods: Towards an Anthropology of Consumption, Routledge, London. 


\section{المجلة الدولية اللملور الآنسانية والإمتماعية International Journal on Humanities and Social Sciences}

website:www.ijohss.com

Email:editor@ijohss.com

ISSN: $2415-4822$

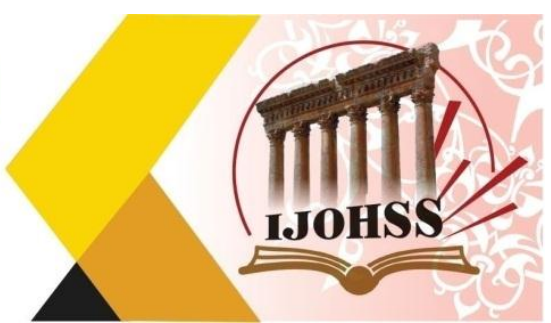

23. Gabrielli, V., Baghi, I., \& Codeluppi, V. (2013). Consumption practices of fast fashion products: a consumer-based approach, Journal of Fashion Marketing and Management, 17, (2), 206-224.

24. Hirschman, E.C. (1981). Comprehending Symbolic Consumption: Three Theoretical Issues, in SV - Symbolic Consumer Behavior, eds. Elizabeth C. Hirschman and Morris B. Holbrook, New York, NY: Association for Consumer Research, Pages: 4-6.

25. Hirschman, E.C., \& Holbrook, M.B. (1982). Hedonic Consumption: Emerging Concepts, Methods and Propositions, Journal of Marketing, 46 (3), 92-101.

26. Leary, M.R., \& Hoyle, R.H. (2009). Handbook of Individual Differences in Social Behavior, The Guilford Press, New York, U.S.A.

27. Leary, M.R., Kelly, K.M., Cottrell, C.A., \& Schreindorfer, L.S. (2013). Construct Validity of the Need to Belong Scale: Mapping the Nomological Network, Journal of Personality Assessment, 95 (6), 610-624.

28. Levy, S. J. (1959). Symbols for Sale. Harvard Business Review, 37tel:(4)117224.

29. Linden, A.R. (2016). An Analysis of the Fast Fashion Industry (Senior Projects). Bard college, Annandale-on-Hudson, New York.

30. Lundblad, L., \& Davies, I. (2016). The values and motivations behind sustainable fashion consumption. Journal of Consumer Behavior, 15, 149-162.

31. Manchiraju, S., \& Sadachar, A. (2014). Personal values and ethical fashion consumption. Journal of Fashion Marketing and Management, 18, 357-374.

32. Morris, C. (1947). Signs, Language and Behavior, George Braziller, Inc, New York.

33. Murphy, C.M., Stosny, S., \& Morrel, T.M. (2005). Change in self-esteem and physical aggression during treatment for partner violent men. Journal of Family Violence, 20 (4), 201-210.

34. Netemeyer, R.G., Burton, S., \& Lichtenstein, D.R. (1995). Trait Aspects of Vanity: Measurement and Relevance to Consumer Behavior. Journal of Consumer Research, 21 (4), 612-626.

35. Niinimäki, K. (2010). Eco-clothing, consumer identity and ideology. Sustainable Development, 18 (3), 150-162.

36. Niinimäki, K., Peters, G., Dahlbo, H., Perry, P., Rissanen, T., \& Gwilt, A. (2020). The environmental price of fast fashion, Nature Reviews Earth \& Environment, 1 (4), 189-200.

37. Prónay, S., \& Hetesi, E. (2016). Symbolic Consumption in Case of Brand Communities, Society and Economy, 38 (1), 87-102.

38. Razzaq, Z., Razzaq, A., Yousaf, S., \& Hong, Z. (2018). The Impact of Utilitarian and Hedonistic Shopping Values on Sustainable Fashion Consumption: The Moderating Role of Religiosity, Global Business Review, 19, 1224 - 1239.

39. Reinders Folmer, C.P. (2016). Social Motives, The SAGE Encyclopedia of Theory in Psychology, 2, 886-890. 


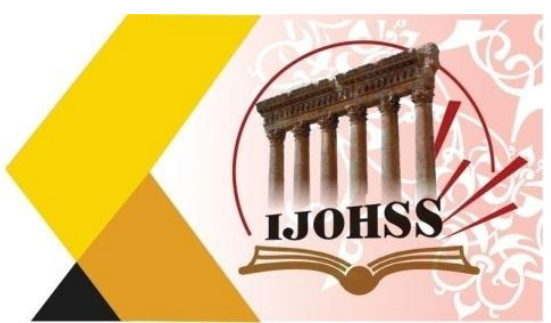

40. Saricam, C., \& Erdumlu, N. (2016). Modeling and Analysis of the Motivations of Fast Fashion Consumers in Relation to Innovativeness, Istanbul Technical University, Faculty of Textile Technologies and Design, Istanbul, Turkey, AUTEX Research Journal, 16 (4), 205-213.

41. Sedikides, C., \& Gregg, A.P. (2003). Portraits of the self. In M. A. Hogg and J. Cooper (Eds.), Sage handbook of social psychology, 110-138. London, UK.

42. Sheth, J.N., Newman, B.I., \& Gross, B.L. (1991). Why we buy what we buy: A theory of consumption values. Journal of Business Research, 22 (2), 159-170.

43. Slade-Brooking, C. (2016). Creating a brand identity: a guide for designers, Laurence King Publishing.

44. Sproles, G.B. (1974). Fashion Theory: A Conceptual Framework. ACR North American Advances. Association for Consumer Research, 463-472.

45. Strahilevitz, M.A., \& Myers, J.A. (1998). Donations to Charity as Purchase Incentives: How Well They Work May Depend on What You are Trying to Sell, Journal of Consumer Research, 24 (4), 434-446.

46. Tawfiq, W.A., \& Ogle, J.P. (2013). Constructing and Presenting the Self Through Private Sphere Dress: An Interpretive Analysis of the Experiences of Saudi Arabian Women, Clothing and Textiles Research Journal, 31 (4), 275-290.

47. Tian, K., Bearden, W.O., \& Hunter, G.L. (2001). Consumers' Need for Uniqueness: Scale Development and Validation. Journal of Consumer Research, 28 (1), 50-66.

48. Yinyin, W. (2011). Consumer Behavior Characteristics in Fast Fashion (Master Thesis). Swedish School of Textiles, University of Borås, Sweden. 